University of Warwick institutional repository: http://go.warwick.ac.uk/wrap This paper is made available online in accordance with publisher policies. Please scroll down to view the document itself. Please refer to the repository record for this item and our policy information available from the repository home page for further information.

To see the final version of this paper please visit the publisher's website. access to the published version may require a subscription.

Author(s): Wiji Arampulam with Dasgupta, S., Dhillon, A. and Dutta, B Article Title: Electoral Goals and Centre-State Transfers: a theoretical model and empirical evidence from India

Year of publication: 2008

Link to published version:

http://www.elsevier.com/wps/find/journaldescription.cws_home/505546/

description\#description

Publisher statement: none 


\title{
Electoral Goals and Center-State Transfers: A Theoretical Model and Empirical Evidence from India*
}

\author{
Wiji Arulampalam ${ }^{\dagger}$ \\ Sugato Dasgupta ${ }^{\ddagger}$ \\ Amrita Dhillon ${ }^{\S}$ \\ Bhaskar Dutta
}

January, 2008

\begin{abstract}
We construct a model of redistributive politics where the central government is opportunistic and uses its discretion to make transfers to state governments on the basis of political considerations. These considerations are the alignment between the incumbent parties at the central and state levels and whether a state is a swing state or not. A testable prediction from the model is that a state that is both swing and aligned with the central government is especially likely to receive higher transfers. We test this prediction using Indian data for 14 states from 1974-75 to 1996-97. We find that a state which is both aligned and swing in the last state election is estimated to receive $16 \%$ higher transfers than a state which is unaligned and non-swing.
\end{abstract}

JEL Classification: C72, D72

Keywords: Redistributive Politics, Alignment, Swing, Electoral Competition.

\footnotetext{
* An earlier version of the paper, with the same title, was circulated as Dasgupta, Dhillon and Dutta (2000). We are grateful to Pinaki Chakraborty, Avinash Dixit, Amar Nath, Roberto Perotti, Jeffrey Wooldridge, three anonymous referees and a co-editor of the journal, Esther Duflo, for helpful comments, and to Sisir Debnath for substantial help with data collection. Financial support from the Policy Planning Research Unit of the Indian Statistical Institute and the University of Warwick is also gratefully acknowledged. Of course, the usual disclaimer applies.

${ }^{\dagger}$ Department of Economics, University of Warwick, Coventry. Email: Wiji.arulampalam@warwick.ac.uk

${ }^{\ddagger}$ Centre for Economic Studies and Planning, Jawaharlal Nehru University, New Delhi. Email: sugatodasgupta@rediffmail.com

${ }^{\S}$ Corresponding author: Department of Economics, University of Warwick, Coventry CV4 7AL, UK. Email: a.dhillon@warwick.ac.uk.

${ }^{\top}$ Department of Economics, University of Warwick, Coventry. Email: B.Dutta@warwick.ac.uk
} 


\section{Introduction}

The allocation of grants (i.e transfers) from central to sub-national governments has always been an important issue of fiscal federalism. Central government grants help to break the linkage between revenue and expenditure assignments by levels of government and permit the center to pursue various objectives. While the traditional literature on fiscal federalism discusses these objectives from alternative perspectives, it assumes that the central government is a "benevolent planner," interested in maximizing social welfare.

The recent literature on political economy emphasizes the institutional constraints and rigidities under which policies are formulated. In particular, policymakers are typically political parties or politicians, who may be opportunistic and implement policies so as to maximize their chances of re-election, or be partisan and so want to further the interests of their own support groups. Of course, the pattern of transfers implemented by a benevolent government will typically be very different from those followed by opportunistic or partisan governments. While there are a number of theoretical and empirical models of opportunistic governments proposed in the literature, the diverse nature of political variables that are used to proxy the theoretical variables makes it important to test the theory in different settings. Our paper is a contribution in this direction - we focus on a developing country, India.

Specifically, we study the hypothesis that the central government transfers to state governments in India are motivated by political considerations. Our theoretical framework explicitly incorporates the fact that different political parties may be in control of governments at different levels. This is important since the state government stands "between" the central government and the voters in the state. Central grants relax the budget constraints of state governments and permit the state governments to increase their expenditure. To the extent that voters in the state are unsure about how the additional expenditure is financed, the ruling party in the state also benefits from increased central grants.

We assume that central grants are used to finance public projects in the states and that they generate goodwill amongst voters for the ruling party at the center. However, since these grants improve the welfare of the state population, the incumbent in the state also reaps some of the benefits. Of course, if the incumbent in the state and the center happens to be the same party (i.e. the state government is aligned with the central government), then that party derives the entire (electoral) benefit of any additional expenditure in the state. On the other hand, if say party $L$ is in power at the center and party $R$ is in power in state $s$, then some of the electoral benefits of additional expenditure in state $s$ "leaks" to party $R$. This gives party $L$ less of an incentive to give grants to this state.

The central incumbent party in our model seeks to maximize its expected vote share across states. Given this objective, it follows that the central incumbent (and, hence, central grants) will be especially biased in favor of states that are simultaneously aligned and relatively more swing. ${ }^{1}$ We call this the Aligned Swing effect. However, the swing factor may work very differently amongst those states which are ruled by the opposition party. Such swing states may actually be discriminated against since some of the goodwill leaks to the party in power

\footnotetext{
${ }^{1}$ Intuitively (see Section 2 for a formal treatment), we say that state $s$ is relatively more swing than state $l$ if an increase in the goodwill generated by a political party results in a greater increase in its vote share in state $s$ than in state $l$.
} 
at the state and this leakage is costlier if the vote share of the state incumbent rises sharply as a consequence.

We then use the model to analyze the political economy of center-state discretionary transfers in India. ${ }^{2}$ The data provide strong support for the hypothesis that aligned swing states receive higher grants than all other state types.

Our paper is not the first to study such issues: Cox and McCubbins (1986), Dixit and Londregan (1996)(henceforth DL), and Lindbeck and Weibull (1987)(henceforth LW) construct theoretical models of tactical redistribution which describe how political parties design their policy platforms in order to further their electoral goals. DL assume that parties design tactical redistribution programs in order to maximize their (expected) vote share while LW also consider the case where each party's objective is to maximize the probability of winning a majority of the seats. These differences in objectives may matter when the prior distribution of support for the two parties is not symmetric (LW).

Our model differs from the aforementioned papers in two ways. First, both DL and LW discuss competition between two symmetric parties in campaign promises at one level of government. In contrast, we emphasize the presence of an asymmetry due to incumbency specifically, the role of the incumbent party is highlighted whereas the role of the challenger party is suppressed. Second, we assume that there are two levels of government, center and state. The latter feature has more in common with DL (1998). However, our baseline model assumes that voters vote on party lines and do not distinguish between the two levels of government while the focus of DL (1998) is on the issue of divided government. Moreover, DL (1998) assume a symmetric role of state and central governments in redistribution and maintain the assumption of two symmetric parties at each level of government. Our focus on incumbency induced asymmetry allows us to derive the Aligned Swing effect, which is novel to this literature. ${ }^{3}$

Drawing on ideas in DL and LW, a small but growing literature has tested whether variations in central transfers to sub-national units can be accounted for by swing and alignment variables entered separately. Using data on social assistance block grants from the central government to communes in Albania, Case (2001), for example, tests the empirical validity of the predictions implied by the two political objective functions outlined by LW. She concludes that politics does matter in determining the pattern of block grants; in particular, swing communes get higher block grants. Johansson (2003) analyzes data on grants from the central government to the municipalities in Sweden and finds limited support for the hypothesis that intergovernmental grants are influenced by whether the municipality is swing or not. Our paper contributes to this literature by showing the empirical relevance of the interaction effects of the swing and alignment variables for the case of India. ${ }^{4}$

\footnotetext{
${ }^{2} \mathrm{~A}$ part of central grants to states in India is governed by explicit formulas. Discretionary grants refer to the part of central grants which is not governed by these formulas. See Section 3 for details.

${ }^{3}$ All the other models in the literature treat parties as symmetric, an assumption more suited to campaign spending than grants, although Snyder (1989) discusses asymmetry between parties in general. Dasgupta et al (2000) (the earliest version of this paper), was the first to introduce the asymmetry due to incumbency, and show the empirical relevance of the Aligned Swing effect (an alignment-swing interaction) in explaining central transfers in India.

${ }^{4}$ Two related papers that use Indian data are Rao and Singh (2001) and Khemani (2007). Using different transfer variables they both test a bargaining model where alignment and the lobbying power of states are the
} 
The plan of the paper is the following. In section 2, we present the theoretical model while Section 3 contains some institutional details. Section 4 describes the data. Sections 5 and 6 contain the empirical results. Section 7 provides some concluding remarks while the last section is the Data Appendix.

\section{Theoretical Framework}

In this section, we build on the DL and LW models of electoral competition to show how the incumbent party at the center can use center-state transfers to promote its electoral prospects by spreading goodwill among voters for the incumbent party at the center. There are two parties, $L$ and $R$, and two levels of government: center and state. The central incumbent party (assumed to be $L$ ) may be interested in promoting the interests of the party at the state level since a stronger state-level party is more likely to result in better performance in the central elections in that state, but may also be interested in re-election at the central level. It is possible therefore for the central incumbent party to have different objective functions based on whether re-election is at the central or the state level. Our benchmark model focuses on the first case where the central incumbent party is interested in promoting the interests of the $(L)$ party at the state level. We then show that under some assumptions, the predictions are consistent with a central incumbent party which is interested in maximizing its electoral prospects in the central level re-election.

\subsection{Benchmark model}

Electoral competition takes place between two parties, $L$ and $R$, at the state level. The central incumbent is assumed to be interested in promoting the interests of the party at the state level. Without loss of generality, let party $L$ be the incumbent at the center. Let $S^{L}$ be the set of states where the incumbent party is $L$, while $S^{R}$ is the set of states where $R$ is the incumbent.

Transfers from the center to each state $s$ are used to finance development projects in the state. These projects increase state incomes, and so the transfers generate some goodwill amongst voters in the state. Since these grants are channelled through the state governments (which also implement the projects), voters cannot perceive perfectly that it is the central government (and therefore the $L$ party) which is the source of a grant. Hence, the goodwill generated by these grants is shared by both tiers of government, or more precisely, by the incumbent parties at the two levels of government. Let $\theta \in[0,1]$. Then, $\theta$ represents the share of the goodwill from per capita transfers that accrues to the central incumbent. The variable $\theta$ is known by the central incumbent and assumed to be exogenous in our model. It captures the degree to which voters are aware of the source of a grant: e.g., $\theta$ is likely to be high if a project is named after the Prime Minister or if voters are politically aware. ${ }^{5}$ Of course, if

main independent variables.

${ }^{5}$ Is the central incumbent capable of attracting all of the goodwill generated by the central plan and centrally sponsored schemes that it launches? For some schemes - with names like Rajiv Gandhi (a prominent Congress Party prime minister) or Pradhan Mantri (Prime Minister) in front of the scheme title - it is easy to deduce 
party $L$ is in power in the state then party $L$ receives the entire goodwill (shared between the party at the center and at the state).

Within each state $s$, there is a continuum of voters of mass $N_{s}$ who may differ in their ideologies. A voter $j$ located at $X_{j}$ on the ideology spectrum $[\underline{X}, \bar{X}]$ has preference $X_{j}$ for party $R$ over party $L . X_{j}$ is private information while the cumulative distribution function of $X$ in state $s$, denoted $\Phi_{s}($.$) , is common knowledge. We assume that the p.d.f. \Phi_{s}^{\prime}(X)$ is strictly positive and continuous for all $X \in[\underline{X}, \bar{X}]$. To simplify notation, we assume that $\underline{X}=-\bar{X}$, so that the midpoint is 0 .

Voters in each state vote on the basis of two criteria: ideology and the amount of goodwill received by the parties. Consider a state $s \in S^{L}$ which has received a per capita grant of $g_{s}$ from the center and let voter $j$ in state $s$ be located at $X_{j}$ on the ideology spectrum. Noting that party $L$ has received a total goodwill of $U\left(g_{s}\right)$, with $U(0)=0, U^{\prime}\left(g_{s}\right)>0, U^{\prime \prime}\left(g_{s}\right)<0$, he votes for the $L$ party if:

$$
U\left(g_{s}\right)-X_{j} \geq 0
$$

and he votes for party $R$ otherwise. On the other hand, if $s \in S^{R}$, then party $R$ (being the incumbent at the state level) gets a share of the goodwill $(1-\theta) U\left(g_{s}\right)$ while party $L$ at the center gets only $\theta U\left(g_{s}\right)$. Hence voter $j$ will vote for the $L$ party iff:

$$
\theta U\left(g_{s}\right)-(1-\theta) U\left(g_{s}\right)-X_{j} \geq 0
$$

The inequalities (1) and (2) generate cut-points, $X\left(g_{s}, L\right)$ and $X\left(g_{s}, \theta, R\right)$, for each state such that for $k=L, R$, a voter located at $X_{j}$ in state $s \in S^{k}$ votes for the $L$ party iff $X_{j} \leq X\left(g_{s}, \theta, k\right)$. Note that $\theta$ does not matter for the cut-point of an $L$ state since voting is on party lines regardless of the level of the party. It follows that:

$$
\frac{\partial X\left(g_{s}, L\right)}{\partial g_{s}}=U^{\prime}\left(g_{s}\right), \frac{\partial X\left(g_{s}, \theta, R\right)}{\partial g_{s}}=(2 \theta-1) U^{\prime}\left(g_{s}\right)
$$

The central incumbent engages in tactical redistribution of grants in order to influence the location of the cut-points $X(\cdot, L)$ and $X(\cdot, R)$ among states. Notice that given equation (3), any increase in $g_{s}$ leads to a rightward shift in $X(\cdot, L)$. In other words, an increase in $g_{s}$ to a state $s \in S^{L}$ has an unambiguous effect - it improves the electoral prospect of party $L$. The effect of an increase in $g_{s}$ when $s \in S^{R}$ is ambiguous. Suppose $\theta$ is less than half. Then, more goodwill accrues to party $R$ which is the incumbent in the state than to party $L$, the incumbent at the center. In this case, party $R$ benefits more than party $L$. However, if $\theta$ exceeds half, then the incumbent at the center receives a higher share of the goodwill, and this results in a rightward shift in the cut-point, a shift that is smaller in magnitude than for an $L$ state as long as $\theta<1$ (see equation (3)).

We assume that the tactical redistribution program of the central incumbent is subject to two constraints. First, the total transfers must satisfy an overall budget constraint. Second,

where the money comes from. But, not all schemes are of this type; Saxena and Ravi (2006, p. 3-4), for example, review the performance of selected anti-poverty schemes and highlight the confusion that results from complicated scheme titles that keep changing as well. Our center-state grants data sums up central funding over all central plan and centrally sponsored schemes; so, an assumption of "goodwill leakages" $(\theta<1$ in our theoretical model) is not unreasonable. 
the central incumbent is also interested in maximizing total welfare accruing from grants. We capture this aspect by specifying a function $\gamma\left(g_{s}\right)$, where $\gamma($.$) is the per capita welfare. We$ assume that $\gamma$ is increasing and concave in $g_{s}$.

In the benchmark model, where the center cares about helping the party at the state level, a plausible objective of the central incumbent is to maximize the vote shares across states (or equivalently, maximize a weighted sum of the probability of winning each state):

$$
\Sigma_{s} N_{s} \gamma\left(g_{s}\right)+\Sigma_{s \in S^{L}} N_{s} \Phi_{s}\left(X\left(g_{s}, L\right)\right)+\Sigma_{s \in S^{R}} N_{s} \Phi_{s}\left(X\left(g_{s}, \theta, R\right)\right)
$$

The central incumbent then maximizes its objective function subject to the budget constraint:

$$
\sum_{s} N_{s} g_{s}=B
$$

by choice of grant allocation, $g_{s}$. We assume that the central incumbent's problem has an interior solution. Assumption 1 below ensures that the solution is a global maximum. The first-order condition for a state $s \in S^{L}$ is:

$$
\gamma^{\prime}\left(g_{s}^{*}\right)+\Phi_{s}^{\prime}\left(X\left(g_{s}^{*}, L\right)\right) U^{\prime}\left(g_{s}^{*}\right)=\lambda
$$

and for a state $s \in S^{R}$ :

$$
\gamma^{\prime}\left(g_{s}^{*}\right)+\Phi_{s}^{\prime}\left(X\left(g_{s}^{*}, \theta, R\right)\right)(2 \theta-1) U^{\prime}\left(g_{s}^{*}\right)=\lambda
$$

where $\lambda$ denotes the Lagrange multiplier and $g_{s}^{*}$ is the allocation of grants to state $s$ that is optimal for the central incumbent, $L$.

Before discussing the implications of equations (6) and (7), we consider the following situation. Suppose state $s$ does not receive any grant from the central incumbent. With $g_{s}$ set equal to 0 , notice that the cut-point in state $s$ is pegged at 0 . We interpret the density at the cut-point $0, \Phi_{s}^{\prime}(0)$, to be a measure of how swing state $s$ is. For example, if state $s$ has a higher density than state $l$ at the cut-point 0 - i.e., $\Phi_{s}^{\prime}(0)>\Phi_{l}^{\prime}(0)$ - then this is interpreted as saying that relative to state $l$, state $s$ has a higher proportion of voters who are not ideologically attached to either party ("floating voters" or "independents") and hence is more swing.

Our theoretical propositions relate variations in grant levels across states to variations in states' swing and variations in states' alignment with the central incumbent. However, we need some further notation and extra assumptions in order to state the propositions formally. Consider two states $s, l$ and assume w.l.o.g. that $\Phi_{s}^{\prime}(0)>\Phi_{l}^{\prime}(0)$. Let $\bar{x}_{s l}$ be the first crossing point to the right of zero for the two p.d.f.s $\Phi_{s}^{\prime}, \Phi_{l}^{\prime}$; let $\underline{x}_{s l}$ be the first crossing point to the left of zero for the two p.d.f.s $\Phi_{s}^{\prime}, \Phi_{l}^{\prime} .{ }^{6}$ Given $\bar{x}_{s l}, \bar{g}_{s l}$ is defined to be the grant level such that $X\left(\bar{g}_{s l}, L\right)=\bar{x}_{s l}$; given $\underline{x}_{s l}$ and $\theta<\frac{1}{2}, \underline{g}_{s l}(\theta)$ is defined to be the grant level such that $X\left(\underline{g}_{s l}(\theta), \theta, R\right)=\underline{x}_{s l}$. So, the grant level $\bar{g}_{s l}$ ensures that the resulting cut-point is $\bar{x}_{s l}$; the grant level $\underline{g}_{s l}(\theta)$ ensures that the resulting cut-point is $\underline{x}_{s l}$.

When state $s \in S^{k}, k=L, R$, receives grant $g$ from the central incumbent, let $V_{s}(g, \theta, k)$ denote the per person contribution of the state to the objective function of the central incumbent, given in equation(4). Thus, for state $s \in S^{L}, V_{s}(g, \theta, L)$ is equal to $\gamma(g)+\Phi_{s}(X(g, L))$;

\footnotetext{
${ }^{6}$ If $\Phi_{s}^{\prime}, \Phi_{l}^{\prime}$ do not cross to the right of zero, set $\bar{x}_{s l}$ equal to $\bar{X}$; similarly, if $\Phi_{s}^{\prime}, \Phi_{l}^{\prime}$ do not cross to the left of zero, set $\underline{x}_{s l}$ equal to $\underline{X}$. Clearly, $\Phi_{s}^{\prime}(X)$ strictly exceeds $\Phi_{l}^{\prime}(X)$ when $X \in\left(\underline{x}_{s l}, \bar{x}_{s l}\right)$.
} 
for state $s \in S^{R}, V_{s}(g, \theta, R)$ is equal to $\gamma(g)+\Phi_{s}(X(g, \theta, R))$. We will assume that the functions $\left\{V_{s}(g, \theta, k)\right\}_{s \in S^{k}}, k=L, R$, are concave in $g$.

Assumption 1: For all states $s \in S^{k}, k=L, R, V_{s}(g, \theta, k)$ is concave in $g .^{7}$

Recall that $\left\{g_{s}^{*}\right\}_{s \in S}$ is the allocation of grants that is optimal for the central incumbent, $L$. Proposition 1 considers the case wherein $\theta \leq \frac{1}{2}$ (goodwill leakages are "large") and shows that, regardless of cut-point densities, states that are unaligned with the central incumbent receive lower grants than states that are aligned. This is called the Alignment Effect, and it arises only because in our model the role of incumbent parties is different from challenger parties, in that state incumbents are able to reap the benefits of grants coming from the central government since voters are not able to distinguish the source of the grants.

Proposition 1: Consider two states $s, l$. If $\theta \leq \frac{1}{2}, s \in S^{L}$ and $l \in S^{R}$, then $g_{s}^{*}>g_{l}^{*}$.

Proof The first-order condition for state $s \in S^{L}$ is given in equation (6) and the first-order condition for state $l \in S^{R}$ is given in equation (7). Thus,

$$
\gamma^{\prime}\left(g_{s}^{*}\right)-\gamma^{\prime}\left(g_{l}^{*}\right)=\Phi_{l}^{\prime}\left(X\left(g_{l}^{*}, \theta, R\right)\right)(2 \theta-1) U^{\prime}\left(g_{l}^{*}\right)-\Phi_{s}^{\prime}\left(X\left(g_{s}^{*}, L\right)\right) U^{\prime}\left(g_{s}^{*}\right)
$$

Recall that we have assumed that $\Phi_{s}^{\prime}(X)$ and $\Phi_{l}^{\prime}(X)$ are strictly positive for all $X \in[\underline{X}, \bar{X}]$. Hence, $\theta \leq \frac{1}{2}$ implies that $\Phi_{l}^{\prime}\left(X\left(g_{l}^{*}, \theta, R\right)\right)(2 \theta-1) U^{\prime}\left(g_{l}^{*}\right)-\Phi_{s}^{\prime}\left(X\left(g_{s}^{*}, L\right)\right) U^{\prime}\left(g_{s}^{*}\right)$ is strictly less than 0 . Thus, $g_{s}^{*}>g_{l}^{*}$ follows from the concavity of $\gamma($.$) .$

Consider now a comparison of two states that are both unaligned with the central incumbent. Assuming that equilibrium grants are "small", Proposition 2 shows that $\theta$ determines whether the more swing of the two states is favored or discriminated against by the central incumbent. For concreteness, consider two unaligned states $s, l \in S^{R}$ and assume that $\Phi_{s}^{\prime}(0)$ exceeds $\Phi_{l}^{\prime}(0)$ (i.e., state $s$ is more swing than state $l$ ). Also, let $\theta<\frac{1}{2}$. In this case, the relatively more swing state, $s$, receives lower grants than state $l$. The intuition behind this result is that when voters are unable to distinguish the source of the grants, the credit may go to the state incumbent instead of the central incumbent. Anticipating this, the central incumbent will discriminate against states that are likely to swing the election in the wrong direction. If, on the other hand, $\theta>\frac{1}{2}$, then grant levels are such that $g_{s}^{*}>g_{l}^{*}$. We refer to the swing- $\theta$ interaction in the determination of grants for unaligned states as the Unaligned Swing Effect.

\footnotetext{
${ }^{7}$ If state $s \in S^{L}$ or if $s \in S^{R}$ but $\theta>1 / 2$, then Assumption 1 is satisfied if $\Phi_{s}(X)$ is concave in $X$. If $s \in S^{R}$ and $\theta<1 / 2$, concavity of $\Phi_{s}(X)$ in $X$ does not ensure that Assumption 1 holds. However, the assumption will be satisfied if $\gamma$ is sufficiently concave.
} 
Proposition 2 Suppose Assumption 1 holds. Consider two states $s, l \in S^{R}$ with $\Phi_{s}^{\prime}(0)>$ $\Phi_{l}^{\prime}(0)$. Then, $g_{s}^{*}>g_{l}^{*}$ if $\theta>\frac{1}{2}$ and $0<g_{s}^{*}, g_{l}^{*}<\bar{g}_{s l}$. However, if $\theta<\frac{1}{2}$ and $g_{s}^{*}, g_{l}^{*}<\underline{g}_{s l}(\theta)$, then this conclusion is reversed. ${ }^{8}$

Proof The first-order conditions for states $s, l \in S^{R}$ can be written as follows:

$$
\begin{aligned}
& \frac{\partial V_{s}\left(g_{s}^{*}, \theta, R\right)}{\partial g_{s}}=\Phi_{s}^{\prime}\left(X\left(g_{s}^{*}, \theta, R\right)\right)(2 \theta-1) U^{\prime}\left(g_{s}^{*}\right)+\gamma^{\prime}\left(g_{s}^{*}\right)=\lambda \\
& \frac{\partial V_{l}\left(g_{l}^{*}, \theta, R\right)}{\partial g_{l}}=\Phi_{l}^{\prime}\left(X\left(g_{l}^{*}, \theta, R\right)\right)(2 \theta-1) U^{\prime}\left(g_{l}^{*}\right)+\gamma^{\prime}\left(g_{l}^{*}\right)=\lambda
\end{aligned}
$$

First assume that $\theta>\frac{1}{2}$. Since $\Phi_{s}^{\prime}(X)>\Phi_{l}^{\prime}(X)$ for all $X<\bar{x}_{s l}$, it follows that $\partial V_{s}\left(g_{s}, \theta, R\right) / \partial g_{s}>$ $\partial V_{l}\left(g_{l}, \theta, R\right) / \partial g_{l}$ if $g_{s}=g_{l}<\bar{g}_{s l}$. Concavity of $V_{s}($.$) and V_{l}($.$) in g$ ensures that $g_{s}^{*}>g_{l}^{*}$ when $g_{s}^{*}, g_{l}^{*}<\bar{g}_{s l}$ if the first-order condition is to be satisfied.

Now consider the case when $\theta<\frac{1}{2}$. Observe that if $g<g_{s l}(\theta)$, then $\partial V_{s}(g, \theta, R) / \partial g_{s}<$ $\partial V_{l}(g, \theta, R) / \partial g_{l}$ because $(2 \theta-1) U^{\prime}(g)<0$ and $\Phi_{s}^{\prime}(X(g, \theta, R))>\Phi_{l}^{\prime}(X(g, \theta, R))$. The proposition follows from the concavity of $V_{s}($.$) and V_{l}($.$) in g$.

We next contrast two states that are both aligned with the central incumbent. Proposition 3 states that so long as equilibrium grants are "small", the state which is more swing receives higher central grants than the state which is less swing.

Proposition 3 Suppose Assumption 1 holds. Consider two states, $s, l \in S^{L}$. If $\Phi_{s}^{\prime}(0)>\Phi_{l}^{\prime}(0)$ and $0<g_{s}^{*}, g_{l}^{*}<\bar{g}_{s l}$, then $g_{s}^{*}>g_{l}^{*}$.

Proof The first-order conditions of states $s, l \in S^{L}$ can be written as follows:

$$
\begin{aligned}
& \frac{\partial V_{s}\left(g_{s}^{*}, \theta, L\right)}{\partial g_{s}}=\Phi_{s}^{\prime}\left(X\left(g_{s}^{*}, L\right)\right) U^{\prime}\left(g_{s}^{*}\right)+\gamma^{\prime}\left(g_{s}^{*}\right)=\lambda \\
& \frac{\partial V_{l}\left(g_{l}^{*}, \theta, L\right)}{\partial g_{l}}=\Phi_{l}^{\prime}\left(X\left(g_{l}^{*}, L\right)\right) U^{\prime}\left(g_{l}^{*}\right)+\gamma^{\prime}\left(g_{l}^{*}\right)=\lambda
\end{aligned}
$$

Since $\Phi_{s}^{\prime}(X)>\Phi_{l}^{\prime}(X)$ for all $X<\bar{x}_{s l}$, it follows that $\partial V_{s}\left(g_{s}, \theta, L\right) / \partial g_{s}>\partial V_{l}\left(g_{l}, \theta, L\right) / \partial g_{l}$ if $g_{s}=g_{l}<\bar{g}_{s l}$. Concavity of $V_{s}($.$) and V_{l}($.$) in g$ ensures that $g_{s}^{*}>g_{l}^{*}$ when $g_{s}^{*}, g_{l}^{*}<\bar{g}_{s l}$ if the first-order condition is to be satisfied.

Consider now two states, $s$ and $l$, where state $s$ is aligned with the central incumbent and more swing than state $l$. Proposition 1 demonstrates that if state $l$ is unaligned with the central incumbent and $\theta \leq \frac{1}{2}$, then equilibrium grants are larger in state $s$ than in state $l$. Intuition, based on considerations of swing and alignment, suggests that the central incumbent

\footnotetext{
${ }^{8}$ When $\theta=\frac{1}{2}$, grants to state $s, l \in S^{R}$ do not affect the two cut-points, which are fixed at 0 . Hence, the first-order conditions for the two states are $\gamma^{\prime}\left(g_{s}^{*}\right)=\lambda$ and $\gamma^{\prime}\left(g_{l}^{*}\right)=\lambda$; i.e., $g_{s}^{*}=g_{l}^{*}$.
} 
would continue to favor state $s$ relative to state $l$ even when $\theta>\frac{1}{2}$. A formal result to this effect can be derived once Assumption 2 is invoked.

Assumption 2: Consider any two states $s, l$ such that $s \in S^{L}, l \in S^{R}$ and $\Phi_{s}^{\prime}(0)>\Phi_{l}^{\prime}(0)$. Let $\theta>\frac{1}{2}$ and $a \equiv(2 \theta-1)$. Then, $a \Phi_{l}^{\prime}(a x) \leq \Phi_{l}^{\prime}(x)$ for all $x \in\left[0, \bar{x}_{s l}\right) .^{9}$

Proposition 4 Suppose Assumptions 1 and 2 hold. Consider two states, $s, l$ such that $s \in S^{L}$ and $l \in S^{R}$. If $\Phi_{s}^{\prime}(0)>\Phi_{l}^{\prime}(0), 0<g_{s}^{*}, g_{l}^{*}<\bar{g}_{s l}$ and $\theta>\frac{1}{2}$, then $g_{s}^{*}>g_{l}^{*}$.

Proof Since $\Phi_{s}^{\prime}(X)>\Phi_{l}^{\prime}(X)$ for all $X<\bar{x}_{s l}$, it follows that $\partial V_{s}(g, \theta, L) / \partial g_{s}>\partial V_{l}(g, \theta, L) / \partial g_{l}$ if $g<\bar{g}_{s l}$ (refer to equations (11) and (12)).

Observe that if $g<\bar{g}_{s l}, \partial V_{l}(g, \theta, L) / \partial g_{l}=\Phi_{l}^{\prime}(X(g, L)) U^{\prime}(g)+\gamma^{\prime}(g)$ is weakly greater than $\partial V_{l}(g, \theta, R) / \partial g_{l}=\Phi_{l}^{\prime}(X(g, \theta, R))(2 \theta-1) U^{\prime}(g)+\gamma^{\prime}(g)$ because $X(g, \theta, R)=(2 \theta-1) U(g)$, $X(g, L)=U(g), U(g)<\bar{x}_{s l}$, and Assumption 2 holds.

We have therefore established that $\partial V_{s}(g, \theta, L) / \partial g_{s}>\partial V_{l}(g, \theta, R) / \partial g_{l}$ if $g<\bar{g}_{s l}$. The proposition follows from the concavity of $V_{s}(g, \theta, L)$ and $V_{l}(g, \theta, R)$ in $g$.

Propositions 1, 3 and 4 yield the following conclusion. Consider a state $s$ that is aligned and more swing than state $l$ (i.e., $\Phi_{s}^{\prime}(0)>\Phi_{l}^{\prime}(0)$ ). Then so long as equilibrium grants are "small", state $s$ receives higher central grants than state $l$, regardless of the alignment of state l. We refer to this feature of the optimal grant allocation as the Aligned Swing Effect.

Finally, note that if $\theta$ was endogenous and subject to manipulation by the central incumbent, then it would want to reveal information about the source of grants in unaligned states: hence, discretionary grants in unaligned states might be skewed in favor of grants that are "targeted" in the sense that it is clear to voters where the grants come from. Once $\theta$ is made endogenous, the role of state level incumbent politicians in trying to change $\theta$ cannot be ignored as well. We leave these extensions for future work. What we can say unambiguously is that if all grants are targeted (i.e., provide information regarding the source of the grant, $\theta=1$ ), then alignment does not matter and only swing states are favored. We refer to the exclusive importance of swing in determining the optimal allocation of targeted grants as the Swing Effect for targeted grants.

Proposition 5 Suppose Assumption 1 holds. Consider two states, s, l. If $\Phi_{s}^{\prime}(0)>\Phi_{l}^{\prime}(0)$, $0<g_{s}^{*}, g_{l}^{*}<\bar{g}_{s l}$, and all grants are targeted $(\theta=1)$, then $g_{s}^{*}>g_{l}^{*}$.

Proof If $\theta=1$, the two cut-point equations (1) and (2) are the same. Hence, the first order conditions, equations (6) and (7), are also the same for all states. The results from Proposition 2 therefore apply to all states regardless of alignment.

\footnotetext{
${ }^{9}$ What this rules out is $\Phi_{l}^{\prime}($.$) declining in \left[0, \bar{x}_{s l}\right)$ at too rapid a rate. Let $\underline{m}$ denote the minimum value attained by $\Phi_{l}^{\prime}(x)$ in the interval $\left[0, \bar{x}_{s l}\right]$. Since $\Phi_{l}^{\prime}$ is strictly positive and continuous, $\underline{m}>0$. It is easy to show that Assumption 2 is implied if: $\left|\Phi_{l}^{\prime \prime}(x)\right| \leq r$ for all $x \in\left[0, \bar{x}_{s l}\right)$ such that $\Phi_{l}^{\prime \prime}(x)<0 ; r=\underline{m} /\left(a * \bar{x}_{s l}\right)$.
} 


\subsection{Extension of the benchmark model}

Suppose now that the central incumbent has a different objective function: it seeks to maximize the chances of its own re-election at the central level. We assume that grants from the central incumbent cannot be given directly to the constituency level - even if grants are made by central ministries ${ }^{10}$, they can be targeted at particular constituencies only through the purpose of the grants (e.g., village road building would benefit all rural constituencies which do not have roads but finer partitions are not possible).

We assume also that voters vote on party lines at both central and state level elections. This means, in particular, that ideology of voters at the state level election is the same as at the central level election, and so is the distribution of ideology on the interval $[\underline{X}, \bar{X}]$. Hence, cut-points are determined exactly as before for each state: states that are relatively more swing at state level elections remain relatively more swing at central level elections. If the central incumbent has the same objective function i.e. to maximize its vote shares across states in the central level election, then we get the same predictions as in Propositions 1-5, but for central elections.

To summarize, when the objective function of the central government is to get re-elected through maximizing the vote shares across states and voters are assumed to vote on party lines, then the predictions of Propositions 1-5 still hold.

\section{Institutional Details}

In this section, we present some relevant facts about political institutions in India, outline the electoral history of political parties since independence in 1947, discuss the basic structure of center-state transfers, and provide examples of central government schemes financed by the central grant category on which our paper focuses.

\subsection{Political Institutions}

\subsubsection{Electoral Rules}

India has a parliamentary democracy at both the central and state levels. The central parliament, the Lok Sabha, has 543 members. The country is divided into 543 separate geographical areas (that is, Lok Sabha constituencies), each of which returns one Member of Parliament. The size and shape of the Lok Sabha constituencies are determined by an independent Delimitation Commission. The Commission ensures that Lok Sabha constituencies strictly respect state boundaries and, as near as is practicable, have the same population. This means, of course, that the number of Lok Sabha constituencies assigned to a state is in rough proportion to its population.

Given single-member constituencies, elections to the Lok Sabha use the first-past-thepost system: a voter in a specific constituency casts a vote for one of the candidates up for election in that constituency; the candidate mustering the most votes is declared the election winner. While most candidates stand as Independents (that is, without formal affiliation with

\footnotetext{
${ }^{10}$ For example, the central plan scheme and centrally sponsored scheme categories of discretionary grants discussed in the section on Institutional Details.
} 
any political party), successful candidates are usually representatives of recognized political parties. ${ }^{11}$

State governments have their own parliament, the Vidhan Sabha, with assembly size depending on state population (Uttar Pradesh has 425 members and Haryana, 90). The procedures for Vidhan Sabha elections exactly mirror those for central elections. Each state is divided into single-member Vidhan Sabha constituencies (the boundaries of Vidhan and Lok Sabha constituencies are different) and the first-past-the-post system is used.

\subsubsection{Government Formation}

Once Lok Sabha election outcomes are declared and there is a single-party majority, the party with the largest number of seats is invited by the president of India to form the central government. When there is no clear majority, coalitions with sufficiently large support can form the government. The government that eventually forms, whether single-party or coalition, must command the confidence of a majority of the Lok Sabha members.

The constitution of India mandates that a national legislative assembly have a normal term of five years from the date appointed for its first sitting. Hence, Lok Sabha elections must be held every five years, unless called earlier. Two circumstances lead to mid-term (that is, early) elections. First, a government may lose the confidence of the Lok Sabha. The president of India, upon verifying that no claimant can form an alternative government claiming majority support, conventionally calls for fresh elections. Second, a government may, principally for electoral gains, voluntarily petition the president of India to dissolve the Lok Sabha and hold mid-term elections; by convention, such recommendations are consented to. For the period that we study (financial year 1974-75 to 1996-97), Lok Sabha elections took place in 1977, 1980, 1984, 1989, 1991 and 1996.

The rules for government formation at the state level are identical to those at the center. Once Vidhan Sabha election outcomes are declared, the governor of the state invites the party with the largest number of seats to form the state government, which must command the support of a majority of the Vidhan Sabha members. The constitution of India stipulates that the normal term of a state legislative assembly is five years from the date appointed for its first sitting. Hence, Vidhan Sabha elections are normally held every five years, unless called earlier. ${ }^{12}$ State elections were formally de-linked from central elections in 1969, when several states held mid-term elections.

\footnotetext{
${ }^{11}$ For the period that we study (financial year 1974-75 to 1996-97), Independent candidates constituted 60.7 percent of all candidates contesting Lok Sabha elections; however, Independent candidates won just 1.4 percent of Lok Sabha constituencies.

${ }^{12}$ Three circumstances lead to mid-term Vidhan Sabha elections. First, a state government can lose the confidence of a majority in the state legislature. The governor of the state, upon verifying that no claimant can form a government commanding majority support, calls for fresh elections. Second, the president of India, upon receipt of a report by the governor of the state or otherwise, may be satisfied that constitutional breakdown has occurred at the state level. This leads to the temporary imposition of President's Rule and, eventually, fresh elections. Third, a state government may voluntarily petition the governor of the state to dissolve the Vidhan Sabha and hold mid-term elections; by convention, such recommendations are consented to.
} 


\subsection{Electoral History}

The electoral history of India divides into two distinct phases. In the first phase, which spanned the years from independence in 1947 until 1967, the Congress Party monopolized the electoral landscape: indeed, in this period, the Congress Party never obtained less than 70 percent of the seats in any Lok Sabha election and won all but two Vidhan Sabha elections. ${ }^{13}$ However the confluence of several crises between 1962 and 1966 (two severe droughts, an unpopular currency devaluation, the death of party stalwarts such as Jawaharlal Nehru, and so on) ensured that the Lok and Vidhan Sabha elections of 1967 marked the beginning of a new phase in Indian politics: the Congress Party lost 78 seats in the Lok Sabha election and retained a majority of just 23 seats; subsequently in the Vidhan Sabha elections, nonCongress governments came to power in five states. The post-1967 era has beheld lively inter-party competition for seats at both the central and state levels.

Our theoretical model assumes that there are two parties: in reality of course India has many parties, some of which may differ at the state and central levels. However, for the period that we study, Table 1 shows that the Congress Party has been in power at the center except for three phases: 1977-1980 (when the Janata Party was in power), 1989-1991 (when a coalition called the National Front was in power), and 1996-1997 (when a coalition called the United Front was in power). Adding up these three phases, the Congress Party was in power at the center for all but a total of 4 years and 2 months. In the main, state elections have witnessed two-party contests. For the period under review, the Congress Party was the dominant party, engaged in competition with different parties in different states.

\subsection{Fiscal Structure of States and Center-State Transfers}

We now briefly outline relevant aspects of the fiscal structure of state governments. The revenue receipts of a state government derive from three sources: tax revenues raised by the state government (e.g., through levying taxes on commodities), non-tax revenues raised by the state government (e.g., from state lotteries), and transfers from the center. There are three major channels through which the center transfers funds to state governments. These are

(i) tax devolution and grants by the Finance Commission,

(ii) grants by the Planning Commission, and

(iii) transfers on account of various central plan and centrally sponsored schemes by various central ministries.

Category (i): The constitution of India specifies that the states are entitled to a share of the tax revenues collected by the center; the aggregate share as well as the distribution amongst the states is decided by Finance Commissions which are appointed at periodic intervals. Successive Finance Commissions recommend explicit formulas to determine the allocation of central

\footnotetext{
${ }^{13}$ The electoral dominance of the Congress Party stemmed from at least two sources. First, the party was universally admired for being the principal representative of the nationalist cause in pre-1947 India. Second, the organizational network of the Congress Party was vastly superior to that of any other political party (see Kothari (2001) for details).
} 
tax revenues amongst states. While these Finance Commission awards have been criticized from time to time, it is generally agreed that the formulas are not influenced by political considerations. In addition to tax devolution, Finance Commissions are also required to recommend grants to the states in need of assistance under Article 275 of the constitution of India.

Category (ii): A sizeable proportion of central grants are also channelled through the Planning Commission. From 1969, plan transfers have been effected on the basis of a formula decided by the National Development Council, which is chaired by the prime minister and contains all cabinet ministers at the center, chief ministers of the states, and members of the Planning Commission. Since grants on account of state plan schemes are based on this consensus formula, we exclude them from the category of discretionary grants to the states. ${ }^{14}$

Category (iii): Central government ministries initiate a number of national programs (e.g., family planning) either by themselves or at the request of state level ministries. The specific purpose transfers given to states through central plan schemes and centrally sponsored schemes have attracted the sharpest criticism because these are essentially completely discretionary. ${ }^{15}$ Central plan schemes are funded entirely by the center, the states merely exercising an agency role in executing these programs. Centrally sponsored programs involve some element of cost-sharing between the center and the concerned state.

Our empirical model only considers grants which come under category (iii), thus explicitly ignoring the general purpose and largely formula-based grants in categories (i) and (ii). ${ }^{16,17}$ This choice of the grant variable is dictated by two considerations. First, category (iii) grants are undoubtedly the most discretionary grants among those listed above. Second, category (iii) grants fit better with our theoretical model which has a central government unilaterally choosing grants rather than bargaining between the center and states.

\subsection{Examples of Central Plan Scheme and Centrally Sponsored Scheme Grants}

There are a large number of central plan and centrally sponsored schemes in place. Examples of such schemes can be seen from the websites of the respective ministries. The Ministry of Rural Development (http://rural.nic.in/) talks about a scheme called "Bharat Nirman" under which there are targets set down for electrification of villages, telephone connectivity, provision of clean water to villages, and so on. The Ministry of Power has the responsibility for the

\footnotetext{
${ }^{14}$ Central assistance on account of state plan schemes has a large loan component as well. Central loans on account of state plan schemes augment a state's capital receipts.

${ }^{15}$ In fact, Rao and Singh (2001) define discretionary central grants to be those that exclusively finance these two scheme types.

${ }^{16}$ Central assistance on account of central plan and centrally sponsored schemes has a small loan component. We disregard this loan component in our empirical analysis since the loan rates are hardly subsidized.

${ }^{17}$ We note that our paper complements Khemani (2007), which focuses instead on central transfers under categories (i) and (ii).
} 
electrification plan through a program called "Rajiv Gandhi Vidyutikaran Yojana" and the agency for implementation is the Rural Electrification Corporation, a public sector agency, rather than the state government. On the other hand, for drinking water, the scheme is a centrally sponsored scheme where state governments contribute 50 percent of the funds and have a role in the targeting of beneficiaries. Examples of other schemes under the Ministry of Rural Development include "Swarnajayanti Gram Swarozgar Yojana" (which provides bank finance so that beneficiaries can buy productive assets and be self-employed) and "Indira Aawas Yojna" (which provides houses to households below the poverty line).

\section{The Data}

The data set for our study consists of annual observations spanning the financial years 1974-75 to 1996-97 for the 14 major states of India. Thus, we exclude from our study the so-called special category states that receive exceptionally generous financial treatment from the Indian government on account of their specific problems (see Rao and Singh (2001) for further details) and the tiny state of Goa, which was upgraded from union territory status as recently as 1987. ${ }^{18}$ In financial year 1996-97, the 14 major states accounted for 83.1 percent of India's land area, 93.3 percent of her population, and 92.6 percent of the domestic product. The details on sources of data and the method of construction of variables are provided in the Data Appendix.

The grant variable that we use is defined as the per capita sum of central plan scheme and centrally sponsored scheme grant levels in constant prices (1980-81 rupees). Column [1] of Table 2 provides state-specific means and standard deviations of this grant variable computed over the sample period. There is enormous across-state variation in the levels of per capita grants. For example, per capita grants average 115.61 rupees in Rajasthan (high) and 38.69 rupees in West Bengal (low).

The set of explanatory variables are partitioned into two distinct categories. The first category, referred to as political controls, measures political attributes of states that are likely to influence central grant awards. The second category, referred to as other controls, measures ostensibly non-political attributes of states (e.g., per capita state domestic product) that capture the need for central assistance.

\subsection{Political Controls}

There are four main predictions from our benchmark theoretical model: (i) Alignment Effect, (ii) Aligned Swing Effect, (iii) Unaligned Swing Effect, and (iv) Swing Effect for targeted grants. Prediction (i) says that when the fraction of goodwill received by the incumbent at the center, $\theta$, is low, then independent of swing, an aligned state receives higher grants relative to an unaligned state. Prediction (ii) states that an aligned and swing state obtains higher grants relative to a non-swing state, whether aligned with the central incumbent or otherwise.

\footnotetext{
${ }^{18}$ The 14 major states are as follows: Andhra Pradesh, Bihar, Gujarat, Haryana, Karnataka, Kerala, Madhya Pradesh, Maharashtra, Orissa, Punjab, Rajasthan, Tamil Nadu, Uttar Pradesh and West Bengal. In financial year 1996-97, India consisted of 25 states: the 14 above-mentioned major states, Goa, and 10 special category border states.
} 
Prediction (iii) points out that if $\theta$ is high, then a state that is unaligned and swing receives higher grants relative to a state that is unaligned and non-swing. This conclusion is reversed when $\theta$ is low. We are unable to test predictions (i) and (iii) because they depend on the unobservable $\theta$. Since data on targeted grants are not available, we are also unable to test prediction (iv). We discuss below how we translate prediction (ii) into empirically testable hypotheses.

Our political variables are Swing and Alignment. We construct both as dummy variables. The swing dummy is denoted $S W$ : states are therefore categorized as 'swing' ( $S W$ equals one) or 'non-swing' ( $S W$ equals zero). The alignment dummy is denoted $A L$. Consider a linear regression model that includes the interacted regressors $A L * S W, A L *(1-S W)$ and $(1-A L) * S W$ and let $\alpha, \beta$ and $\delta$ be the corresponding coefficients. Then, prediction (ii) implies that $\alpha>0$ and $\alpha-\beta>0$.

In order to proceed with the construction of the two crucial dummy variables, $A L$ and $S W$, we first assume that decisions regarding the allocation of central grants to state $s$ for financial year $t$ are made at the very beginning of that financial year (that is, March 31 of financial year $(t-1)$ ) using state electoral outcome information from the last Vidhan Sabha election as well as the last Lok Sabha election.

We opt for the March 31 decision date because by that time, the amount of aggregate central grants (on account of central plan schemes and centrally sponsored schemes) available for disbursement in the forthcoming financial year is formally recorded in the annual fiscal budget of the central government and there is at least an implicit understanding in the Planning Commission regarding the grant amounts assigned to each of the states. This reasoning notwithstanding, the March 31 deadline is of course somewhat arbitrary. So, in Section 6 we report our results when the central grants-related decision date for financial year $t$ is pegged instead at March 1 of financial year $(t-1)$ (that is, we bring forward the decision date by one month).

We construct the alignment dummy as follows: $A L_{s t}$ is defined as 1 if the central government and the state government of state $s$ on March 31 of financial year $(t-1)$ share at least one political party in common and there is no President's Rule in state $s$ on that date. ${ }^{19,20}$ The state-specific averages for this variable are given in Column [2] of Table 2 and the listing is given in Appendix Table 1. It turns out that the states of Bihar, Gujarat, Haryana, Madhya Pradesh, Maharashtra, Orissa and Uttar Pradesh are highly aligned states. The least aligned state is West Bengal, which had an aligned state government only during the three initial years (1974-75 to 1976-77).

The construction of the alignment dummy may give rise to some concern. Suppose that at the start of financial year $t$, the center and state $s$ are governed by distinct coalitions that have only a minimal party in common. Yet, despite the plainly tenuous overlap between the two coalition governments, we code $A L_{s t}$ to equal 1. Fortunately, such concerns are misplaced

\footnotetext{
${ }^{19}$ Notice that the date used to construct the alignment dummy is the date on which decisions regarding central grant allocations are presumed to be made.

${ }^{20}$ Recall that President's Rule may be imposed on a state when the president of India is satisfied that constitutional breakdown has occurred at the state level. We exclude President's Rule from our definition of the alignment dummy since the center-state relationship during a spell of President's Rule is qualitatively different from that in normal times.
} 
in the Indian context during the period under review. Between financial years 1974-75 and 1996-97, the central government was a coalition for a total of two years and five months. Averaged over the 14 states, coalition governments at the state level accounted for a total of one year and two months. ${ }^{21}$ In most instances, all the parties of a state government coalition were either in power at the center or out of power at the center.

Consider, now, how we create the political control variables that indicate whether a stateyear $(s, t)$ is swing or not. ${ }^{22}$ We construct the swing dummy to satisfy the following criteria: First, it should be a relative measure in line with our theoretical model; and second, it should take account of multi-party contests that are a standard feature of constituency-level elections in India.

Our theoretical model shows that both Vidhan and Lok Sabha election outcomes may affect the flow of central funds. This means that we end up creating two sets of measures of swing for state-year $(s, t)$ - one set is derived from Vidhan Sabha election outcomes while the other is based on Lok Sabha election outcomes - and include interactions between these two sets of swing measures in our empirical model. Consistent with the construction of the alignment dummy, the various swing measures for state-year $(s, t)$ use outcomes from the last Vidhan and Lok Sabha elections as viewed from the decision date pegged at March 31 of financial year $(t-1)$.

Our construction of the swing measures proceeds as follows. Given state-year $(s, t)$, we identify the last Vidhan Sabha and Lok Sabha elections occurring in state $s$ prior to financial year $t .^{23}$ Now, for both elections, we observe the vote shares of the contending political parties in each of the electoral constituencies of state $s$. So, for each election, we first define a variable winmarg, which for electoral constituency $i$ is the difference in the percentage vote shares of the two political parties that secure the highest number of votes in constituency $i$ (see footnote for further details) ${ }^{24}$ this done, we classify electoral constituency $i$ as a 'swing' constituency if its winmarg value is less than or equal to the cutoff value of one percent. Let vswing $01_{s t}$ and lswing $01_{s t}$ denote, respectively, the proportion of such swing constituencies in state $s$ in the identified Vidhan and Lok Sabha elections. Additionally, we create variables vswing $02_{s t}$ to vswing $10_{s t}$ and lswing $02_{\text {st }}$ to lswing $10_{s t}$ as the proportion of constituencies in state $s$ that have winmarg values less than or equal to two percent to 10 percent in the identified Vidhan and Lok Sabha elections. These cutoff values capture the "tightness" of the race in a constituency when multiple parties (two or more) contest the election.

The state-specific means of eight 'proportion of swing constituencies' variables - that is,

\footnotetext{
${ }^{21}$ For each state $s$, we computed the number of months between financial years 1974-75 and 1996-97 during which the state government was a coalition. The average of these numbers over the 14 states is 14 months.

${ }^{22}$ Note that we use "state-year $(s, t)$ " as a shorthand for "state-financial year $(s, t)$.

${ }^{23}$ For concreteness, consider the financial year 1974-75. To obtain the swing measures, we identify the last Vidhan Sabha and Lok Sabha elections occurring before March 31, 1974.

${ }^{24}$ Let there be $K$ political parties contending a Vidhan Sabha election in electoral constituency $i$ of state $s$. Let the votes received by party 1 be $v_{1}$, the votes received by party 2 be $v_{2}$, and so on. If party 1 is highest vote-getter in constituency $i$ and party 2 is the second highest vote-getter in constituency $i$, then winmarg for constituency $i$ in the Vidhan Sabha election under review is $100 \times\left(v_{1}-v_{2}\right) / \sum_{j=1}^{K} v_{j}$. Ideally, we would like to use eligible voting population of constituency $i$ as the denominator in the calculation of its winmarg value since there may be concerns regarding the possible endogeneity of the voter turnout variable. However, in the Indian context, we believe that this is unlikely to be a serious problem; Ghosh (2006) shows that electoral turnout in Lok Sabha constituencies is not robustly explained by the predicted closeness of the election.
} 
vswing01, vswing02, vswing05, vswing 10 , lswing01, lswing02, lswing 05 and lswing10 are provided in Panel [1] of Table 3. Column [1] shows that over our sample period, in the states of Haryana, Kerala and Uttar Pradesh, over six percent of Vidhan Sabha constituencies witnessed elections in which the winning margin (that is, winmarg) was not more than one percent; in marked contrast, the corresponding numbers for the states of Gujarat and West Bengal are less than three percent. Column [2] raises the winning margin to two percent. Notice, now, that over our sample period, over 14 percent of Vidhan Sabha constituencies in Kerala witnessed elections wherein the winning margin was not more than two percent. Panel [1] highlights an important contrast between Vidhan and Lok Sabha elections. Since Vidhan Sabha elections primarily center on local issues, "small" political parties with narrow and localized support bases often contest Vidhan Sabha elections while opting out of Lok Sabha elections. The spreading of votes over a larger set of contending political parties makes the winning margin in Vidhan Sabha elections on average lower than that in Lok Sabha elections. This is best seen by considering the proportion of Vidhan and Lok Sabha swing constituencies averaged over the 14 states in our study: with the winning margin set at one percent, two percent, five percent and 10 percent, the proportions of Vidhan Sabha swing constituencies in the 14 states are, respectively, 0.046, 0.089, 0.220 and 0.411 ; the corresponding proportions for Lok Sabha elections, viz. 0.039, 0.079, 0.174 and 0.345, are uniformly lower.

Although the various 'proportion of swing constituencies' measures enable us to pick up the closeness of Vidhan and Lok Sabha elections in each state, the testing of our model predictions with these variables is not straightforward. Instead, our model testing is based on a set of swing dummies, each of which is derived from the corresponding 'proportion of swing constituencies' variable (vswing $01_{s t}$ is transformed to vswingdum $01_{\text {st }}$, lswing $01_{s t}$ is transformed to lswingdum01 st, and so on). The swing dummies are constructed as follows. Take, for example, the vswing01 variable which refers to Vidhan Sabha elections and uses the one percent cutoff value for the winning margin (that is, winmarg). For financial year $t$, we first calculate the median value of vswing $01_{s t}$ across all states $s$ that have a positive vswing $01_{s t}$. Let this median value be denoted $\operatorname{med}_{t}$. Given $\operatorname{med}_{t}$, we now let vswingdum01 $1_{s t}$ take the value of 1 (respectively, 0) if vswing $01_{s t}$ strictly exceeds (respectively, is weakly less than) med $_{t}$. Notice that under our definition, 50 percent of the states with non-zero values of vswing01 in financial year $t$ are classified as swing states in that year.

The state-specific means of the eight swing dummies (two election types $\times$ four cutoff values for the winning margin) are given in Panel [2] of Table 3. Consider Column [1] of Panel [2]. With the winning margin set at one percent, the relevant swing dummies are vswingdum01 and lswingdum01. Now, focus on the state of Bihar. Column [1] indicates that out of the 23 sample years, Bihar was coded as a swing state on 17 occasions $(0.739 \times 23)$ using the variable vswingdum01 and coded as a swing state on eight occasions $(0.348 \times 23)$ using the variable lswingdum01. The results in Panel [2] are in conformity with widely held views regarding the political competitiveness of Indian states. With respect to Vidhan Sabha elections, the principal focus of our study, Panel [2] identifies Bihar, Kerala and Uttar Pradesh as highly swing states. Vidhan Sabha elections in Bihar and Uttar Pradesh are multi-party contests and a small vote swing in favor of any one political party leads to vast changes in the seat shares of the contending parties. Vidhan Sabha elections in Kerala, on the other hand, have centered on two pre-poll alliances - one alliance is led by the Congress Party while the 
other is led by the Communist Party of India (Marxist). Over the years, the electoral margins have been razor thin and the two alliances have taken turns in forming the state government.

\subsection{Other Controls}

The set of 'other controls' comprises six regressors: annual rainfall, state population, proportion of state population characterized as scheduled caste or scheduled tribe, per capita state domestic product in constant prices (1980-81 rupees), the share of agriculture in state domestic product, and state's per capita allocation of the proceeds of central taxes, as determined by the Finance Commission, in constant prices (1980-81 rupees). ${ }^{25}$ Summary statistics for these regressors are given in Column [3] to [8] of Table 2.

We briefly outline why we condition the allocation of central grants on the set of 'other controls'. State incomes derived from agriculture depend on rainfall levels; central grants may provide insurance to state governments by responding to rainfall shocks. Rao and Singh $(1998,2001)$ argue that state population per se is frequently a measure of political influence; central grants may therefore be disproportionately skewed towards populous states. Scheduled castes and scheduled tribes represent historically disadvantaged groupings of citizens; equity considerations could induce a positive relationship between grant awards and the share of such groups in states' population. Equity concerns also lead us to believe that poorer states will receive more of the central pie than richer states. Chakraborty (2003), on the other hand, argues that state income is a good proxy for lobbying power. This suggests that central transfers in India may actually be regressive. Farmers and industrialists represent distinct lobbies with disparate interests. The strengths of these two groups play a role in determining whether industrial states are favored in terms of grant awards relative to agricultural states. Alternatively, public investments may have greater value in industrial states (e.g., because of higher population density). Here, economic efficiency considerations could induce a negative relationship between the volume of central grants and the share of agriculture in state domestic product. Finally, why do we use the explicitly formula-based per capita allocation of central tax revenues as a regressor? It is generally agreed that the Finance Commission, which determines states' share of central tax revenues, does not exhibit noticeable political bias and instead bases its awards on variables that reflect states' genuine need for central assistance. By using these Finance Commission transfers as a regressor, we ask whether the variables on which we focus - the swing and alignment dummies - account for central grants once we control for states' needs as perceived by the Finance Commission. ${ }^{26}$

\footnotetext{
${ }^{25}$ As pointed out in Section 3, the Finance Commission determines states' shares of central tax revenues and recommends grants-in-aid to states under Article 275 of the constitution of India. We note that the dependent variable "Constitutional Transfers" in Khemani (2007) is the sum of "state's per capita allocation of the central tax proceeds" (a regressor in our empirical model) and "state's per capita allocation of Finance Commission grants."

${ }^{26}$ Of course, it is impossible to establish that the Finance Commission transfers we consider are politically neutral. Therefore, in Section 6 we show that our results are substantively unchanged if we exclude the Finance Commission transfer variable from the set of regressors.
} 


\section{$5 \quad$ Empirical Model and Results}

In our theoretical model, the party in power at the center maximizes the objective function in equation (4) subject to an aggregate budget constraint. The maximization problem yields a behavioral function where the supply of central grants to a particular state depends on the exogenous characteristics of all states. Our empirical work does not estimate this behavioral function. Instead, we record the grants given by the central incumbent to the various states and ask the following question: Is there an association between the central grant awards and the political factors identified by our theoretical model? To this end, we estimate the following log-linear model for grants:

$$
\ln (\text { grants })_{s t}=\beta^{\prime} p_{s t}+\gamma^{\prime} x_{s t}+\alpha_{s}+\delta_{t}+u_{s t}
$$

where grants $_{s t}$ is the per capita real grants (on account of central plan schemes and centrally sponsored schemes) from the center to state $s$ in financial year $t, p_{s t}$ is the vector of political controls, and $x_{s t}$ is the vector of other explanatory variables. To account for unobserved state specific effects, we include state specific dummies, $\alpha_{s}$; similarly, time specific dummies, $\delta_{t}$, are included to account for unobserved time specific effects. The model is estimated using ordinary least squares. The resulting estimators are consistent provided the unobserved state specific and time specific effects are sufficient to account for any possible correlation between the regressors and the error term.

How are the 'political controls' in equation (13) constructed? In Section 4.1, we described an array of swing dummies (vswingdum01, lswingdum01, and so on), each of which was formed on the basis of either Vidhan or Lok Sabha election outcomes. From within this set of swing dummies, a specific empirical model first selects one swing dummy based on Vidhan Sabha election outcomes (call this $V S W$ ) and one swing dummy based on Lok Sabha election outcomes (call this $L S W$ ). This done, the 'political controls' include all relevant interactions between the alignment dummy, $A L$, and the two chosen swing dummies, $V S W$ and $L S W$. For ease of discussion, we write the political effects as follows:

$$
\begin{aligned}
\beta^{\prime} p_{s t}= & \beta_{1} A L_{s t} * V S W_{s t} * L S W_{s t}+\beta_{2} A L_{s t} * V S W_{s t} *\left(1-L S W_{s t}\right)+ \\
& \beta_{3} A L_{s t} *\left(1-V S W_{s t}\right) * L S W_{s t}+\beta_{4} A L_{s t} *\left(1-V S W_{s t}\right) *\left(1-L S W_{s t}\right)+ \\
& \beta_{5}\left(1-A L_{s t}\right) * V S W_{s t} * L S W_{s t}+\beta_{6}\left(1-A L_{s t}\right) * V S W_{s t} *\left(1-L S W_{s t}\right)+ \\
& \beta_{7}\left(1-A L_{s t}\right) *\left(1-V S W_{s t}\right) * L S W_{s t} .
\end{aligned}
$$

Our basic empirical model selects vswingdum01 to be the Vidhan Sabha swing dummy, $V S W$, and lswingdum01 to be the Lok Sabha swing dummy, $L S W$, in equation (14). ${ }^{27}$ Column [2] of Table 4 reports the regression results for the basic model. ${ }^{28}$ Five conclusions follow directly from these results.

\footnotetext{
${ }^{27}$ Recall that vswingdum01 (respectively, lswingdum01) defines a Vidhan Sabha (respectively, Lok Sabha) constituency to be 'swing' if the winning margin is less than or equal to the one percent cutoff value.

${ }^{28}$ Given the focus of our paper, we only present the coefficient estimates related to the political variables in Table 4 . The detailed results are available on request from the authors.
} 
First, we find that the only coefficients that are significantly different from zero are the coefficients on (i) $A L * V S W * L S W$ and (ii) $A L * V S W *(1-L S W)$. A state that is aligned and swing in both the last Vidhan Sabha and the last Lok Sabha elections is estimated to receive 19.6 percent $(\exp (0.179)-1)$ higher central grants than a state that is unaligned and non-swing with respect to both election types (the base case in our empirical model); an aligned state that is swing in the last Vidhan Sabha but non-swing in the last Lok Sabha election is estimated to receive 13.9 percent $(\exp (0.130)-1)$ higher central grants than a state that is unaligned and non-swing with respect to both election types.

Second, it turns out that the null hypothesis $\beta_{1}-\beta_{2}=0$ is not rejected at conventional levels of significance. ${ }^{29}$ Consider, now, an aligned state for which the Vidhan Sabha swing dummy, $V S W$, assumes the value of one. With $\beta_{1}$ equal to $\beta_{2}$, notice that central grants to this state are not conditioned on the value of the Lok Sabha swing dummy, $L S W$. Thus, our empirical findings highlight the key role of Vidhan Sabha election outcomes in determining central transfers. A possible explanation for this is that Vidhan Sabha elections feature many more candidates and are held far more frequently than Lok Sabha elections.

Third, consider a state that is aligned and swing in the last Vidhan Sabha election (the Lok Sabha swing dummy can be either zero or one). The coefficients on the variables in Column [2] indicate that such a state receives higher central grants than a state that is unaligned, regardless of its swing characteristics (see footnote for details). ${ }^{30}$

Fourth, consider a state that is aligned and swing in the last Vidhan Sabha election (the Lok Sabha swing dummy can be either zero or one). The coefficients on the variables in Column [2] indicate that such a state receives higher central grants than a state that is aligned but non-swing, defined here as a state with $V S W$ equal to zero (see footnote for details). ${ }^{31}$

Fifth, conclusions three and four jointly imply that a state with $A L$ and $V S W$ equal to one is favored by the central incumbent relative to a non-swing state ( $V S W$ equal to zero), regardless of its alignment.

For comparison purposes, we also report the baseline regression without 'other (that is, non-political) controls' in Column [1] of Table 4. Comparing Columns [1] and [2], we see that the main coefficient of interest, that on $A L * V S W * L S W$, remains positive and significant when 'other controls' are excluded from the model.

In summary, there is clear evidence of the Aligned Swing Effect emphasized in our theoretical model.

\section{Robustness Issues}

Section 6 consists of two parts. In the first part, we consider several variants of our basic model but do not tinker with the two swing dummies, $V S W$ and $L S W$, used in the construction of the 'political controls'. In the second part, we study how the conclusions in Section 5 are affected when the swing dummies are constructed somewhat differently.

\footnotetext{
${ }^{29}$ Our results show that $\left(\hat{\beta}_{1}-\hat{\beta}_{2}\right)$ is equal to 0.049 with a standard error of 0.054 .

${ }^{30}$ This conclusion follows since standard hypothesis tests establish: (i) $\beta_{1}>0$; (ii) $\beta_{2}>0$; and (iii) $\left(\beta_{i}-\beta_{j}\right)>$ $0, i=1,2$ and $j=5,6,7$.

${ }^{31}$ This conclusion follows since standard hypothesis tests establish: (i) $\left(\beta_{1}-\beta_{3}\right)$ and $\left(\beta_{1}-\beta_{4}\right)$ exceed 0 ; and (ii) $\left(\beta_{2}-\beta_{3}\right)$ and $\left(\beta_{2}-\beta_{4}\right)$ exceed 0 .
} 


\subsection{Variants of the Basic Model}

Recall that our basic model has the following three features: first, we maintained that central grants-related decisions for financial year $t$ are made on the basis of political considerations prevailing on March 31 of financial year $(t-1)$; second, we included state's per capita allocation of central tax revenues, as determined by the Finance Commission, in our set of regressors; and third, the construction of the alignment dummy classified a spell of President's Rule as a period of center-state nonalignment. Consider what happens to our results when these three features of the basic model are changed one at a time.

Variant 1 of the basic model (Column [3] of Table 4) uses March 1 of financial year $(t-1)$ as the date on which central grant allocations for financial year $t$ are decided (see footnote for details). ${ }^{32}$ Shifting the decision date by a month (from March 31 to March 1) leaves the conclusions of the basic model unaltered: as in Section 5, the coefficients that are significantly different from zero are the coefficients on (i) $A L * V S W * L S W$ and (ii) $A L * V S W *(1-L S W)$.

Variant 2 of the basic model (Column [4] of Table 4) excludes the Finance Commission transfers from the set of regressors. While the results in Column [4] are somewhat worse than those in Column [2] (the coefficient on $A L * V S W *(1-L S W)$ is statistically significant at only the 10 percent level and the model's $R^{2}$ goes down), the substantive implications of the two sets of results are broadly similar.

Variant 3 of the basic model (Column [5] of Table 4) constructs the alignment dummy by implicitly classifying a period of President's Rule as a spell of center-state alignment (see footnote for details). ${ }^{33}$ This alteration in the treatment of President's Rule makes little difference to the conclusions of the basic model: while the coefficients in Column [5] are mostly larger than those in Column [2], the same two variables are significant in both cases.

Finally, in Variant 4 (Column [6] of Table 4), we re-estimate the basic model with 'political controls' consisting of three separate regressors: AL, vswing01 and lswing $01 .^{34}$ Two conclusions follow from Column [6] estimates. First, the coefficient on the alignment dummy is not statistically significant from zero, implying that central grants are not conditioned per se on whether a state is aligned or not. The Core Support hypothesis (Cox and McCubbins (1986), Case (2001)) states that the central government uses grants to reward its core support: in Case (2001) this is tested empirically using the proportion of voters in a constituency that vote for the leading party in the national election. Observe that the central incumbent's vote share in the state election (Case's core support measure) and the alignment dummy are positively correlated so that ceteris paribus, aligned states have higher core support than un-

\footnotetext{
${ }^{32}$ The shift in the decision date from March 31, as in the basic model, to March 1 forces us to redefine the variables comprising 'political controls' in the following two ways: (i) the dummy variable $A L_{s t}$ is now coded as 1 if the central government and the government of state $s$ on March 1 of financial year $(t-1)$ share at least one political party in common and there is no President's Rule in state $s$ on that date; and (ii) the construction of the various swing measures for state-year $(s, t)$ is based on the last Vidhan and Lok Sabha elections occurring in state $s$ before March 1 of financial year $(t-1)$.

${ }^{33}$ Fix a state-year $(s, t)$. Then, $A L_{s t}$ in Variant 3 of the basic model is coded as 1 if the central government and the government of state $s$ on March 31 of financial year $(t-1)$ share at least one political party in common or there is President's Rule in state $s$ on that date.

${ }^{34}$ Recall that vswing $01_{s t}$ and lswing $01_{s t}$ are, respectively, the proportion of 'swing' constituencies (defined with respect to the one percent cutoff value for the winning margin) in the last Vidhan and Lok Sabha elections in state $s$ occurring prior to financial year $t$.
} 
aligned states. Hence, one test of the Core Support hypothesis would be that alignment (by itself) matters for grants. Our first conclusion therefore suggests that there is no evidence for the Core Support hypothesis. ${ }^{35}$ Second, the coefficient on vswing01 is positive and significantly different from zero. So, an increase in the proportion of swing constituencies in the last Vidhan Sabha election increases the central grants received by a state.

\subsection{Varying the Cutoff Value}

The results in Section 5 show that Lok Sabha election outcomes do not impact central transfers. So, we re-estimate the basic model given in Column [2] of Table 4 without the Lok Sabha swing dummy, $L S W$. Column [1] of Table 5 provides the regression estimates.

Before discussing these estimates, we observe that the 'political controls' of our empirical model now consists of three interacted variables: $A L * V S W, A L *(1-V S W)$ and $(1-A L) *$ $V S W$. Let $\beta_{1}, \beta_{2}$ and $\beta_{3}$ denote, respectively, the coefficients on $A L * V S W, A L *(1-V S W)$ and $(1-A L) * V S W$. Two main conclusions follow from Column [1] estimates. First, we note that the only coefficient that is significantly different from zero is the coefficients on $A L * V S W$. A state that is both aligned and swing in the last Vidhan Sabha election is estimated to receive 16 percent $(\exp (0.148)-1)$ higher grants than a state that is unaligned and non-swing in the last Vidhan Sabha election (the base case in our empirical model). Second, it turns out that $\left(\beta_{1}-\beta_{2}\right)$ is positive and significantly different from zero. This means that within the set of aligned states, states that are swing in the last Vidhan Sabha election receive higher central grants than states that are non-swing in the last Vidhan Sabha election. The two above conclusions jointly imply that an aligned and swing state is favored by the central incumbent relative to a state that is non-swing, regardless of its alignment. Summing up, the evidence suggests that the allocation of central transfers in India satisfies the Aligned Swing Effect property of our theoretical model.

Finally, we consider how our findings change as we vary the construction of the Vidhan Sabha swing dummy, $V S W$. Columns [2] to [4] of Table 5 report the regression results when the Vidhan Sabha swing dummy is, respectively, vswingdum02, vswingdum05 and vswingdum $10 .{ }^{36}$ The results in Table 5 show that when the cutoff value for the winning margin, used to decide whether a constituency is 'swing' or not, is raised from one percent, the coefficient on $A L * V S W$ remains positive in sign; however, statistical significance is lost. This suggests that only Vidhan Sabha constituencies witnessing especially close elections affect grant allocations of the central incumbent.

\footnotetext{
${ }^{35}$ Another way to empirically test the Core Support hypothesis would be to use the proportion of MPs in the state that are from the ruling party at the center as a measure of core support. When we estimated this specification, the effect of the core support measure was found to be insignificant. The results are available on request from the authors.

${ }^{36}$ Recall that vswingdum02, vswingdum05 and vswingdum10 define a Vidhan Sabha constituency to be 'swing' if the winning margin is, respectively, less than or equal to the cutoff value of two percent, five percent and 10 percent.
} 


\section{Conclusion}

This paper constructs a model of redistributive politics where the central government is opportunistic and uses its discretion to make grants to state governments on the basis of political considerations. These considerations are the alignment between the incumbent parties at the central and state levels and whether a state is a swing state or not. The main testable prediction from the model is that a state that is both swing and aligned with the central government receives higher grants relative to a state that is non-swing, whether aligned with the central government or otherwise. We test this prediction using Indian data for 14 states from 1974-75 to 1996-97. We find that a state which is both aligned and swing in the last state election is estimated to receive 16 percent higher grants than a state which is unaligned and non-swing.

Many empirical questions remain to be explored. Our study is confined to the analysis of explicit center-state transfers in India. Yet, intergovernmental transfers in India are frequently implicit (e.g., subsidized borrowing by states from the central government). A future study could estimate the extent to which political factors account for such transfers. Biswas and Marjit (2000) represent a start on this problem. They show that states' representation in the central government cabinet affects the statewise distribution of industrial licenses.

Finally, we have tested but one half of the complete story. Specifically, while central governments' grant decisions were analyzed, voter behavior was left unaddressed. Does the electorate, at the sub-national level, condition its vote on central grants? Some evidence, employing US data, already exists. Levitt and Snyder (1997) demonstrate that central spending in a House district enhances the vote share of the incumbent member of Congress. Stein and Bickers (1994) use survey data to establish that a voter is more likely to support the incumbent House candidate when she is aware of new central grant awards to her district. Comparable

work with Indian data is non-existent. In sum, the analysis of voter behavior in India remains a fruitful research topic. 


\section{References}

1. Biswas R, Marjit S. Political lobbying and discretionary finance in India: An aspect of regional influence in a representative democracy. Centre for Studies in Social Sciences mimeo 2000.

2. Butler D, Lahiri A, Roy P. India Decides, Elections 1952-1995. New Delhi: Living Media India Limited 1996.

3. Case A. Election goals and income redistribution: Recent evidence from Albania. European Economic Review 2001;45; 405-423.

4. Chakraborty P, Unequal fiscal capacities across Indian states: How corrective is the fiscal transfer mechanism? National Institute of Public Finance and Policy mimeo 2003.

5. Cox G, McCubbins M. Electoral politics as a redistributive game. Journal of Politics $1986 ; 48 ; 370-389$.

6. Dasgupta S, Dhillon A, and Dutta B. Electoral goals and center-state transfers: A theoretical model and empirical evidence from India. Department of Economics, University of Warwick mimeo 2000.

7. Dixit A, Londregan J. The determinants of success in redistributive politics. Journal of Politics 1996; 58; 1132-1155.

8. Dixit A, Londregan J. Fiscal federalism and redistributive politics. Journal of Public Economics 1998; 68; 153-180.

9. Ghosh S. The phenomenon of voter turnout in the parliamentary elections of India. Contemporary Issues and Ideas in Social Sciences 2006;2; 1-35.

10. Government of India, Ministry of Planning, Department of Statistics. 1974-1996. National Accounts Statistics. Central Statistical Organization: New Delhi.

11. Government of India, Ministry of Planning, Department of Statistics. Statistical Abstract of India. 1974-1996; Central Statistical Organization: New Delhi.

12. Government of India, Office of the Registrar General. Various Years. Census of India.

13. Grover V, Arora R. (eds). Encyclopedia of India and Her States; 1998. Deep and Deep Publications: New Delhi.

14. Johansson E. Intergovernmental grants as a tactical instrument: Some empirical evidence from Swedish municipalities. Journal of Public Economics 2003;87; 883-915.

15. Khemani S. Does delegation of fiscal policy to an independent agency make a difference? Evidence from intergovernmental transfers in India. Journal of Development Economics $2007 ; 82 ; 464-484$.

16. Kothari R. Politics in India 2001. Orient Longman Limited: New Delhi. 
17. Levitt S, Snyder J. The impact of federal spending on House election outcomes. Journal of Political Economy 1997;105: 30-53.

18. Lindbeck A, Weibull J. Balanced-budget redistribution as the outcome of political competition. Public Choice 1987;52; 273-297.

19. Rao G, Singh, N. An analysis of explicit and implicit intergovernmental transfers in India." Department of Economics, University of California at Santa Cruz, mimeo 1998.

20. Rao G., and N. Singh. The political economy of center-state fiscal transfers in India. Department of Economics, University of California at Santa Cruz mimeo 2001.

21. Reserve Bank of India. Reserve Bank of India Bulletin 1974-1996. Reserve Bank of India: Mumbai.

22. Saxena N, Ravi J. Rural poverty reduction through centrally sponsored schemes. Concept paper 2006. Downloaded from the website of the National Advisory Council, Government of India (http://nac.nic.in/).

23. Snyder J. Election goals and the allocation of campaign resources. Econometrica 1989;57; 637-660.

24. Stein R, Bickers K. Congressional elections and the pork barrel. Journal of Politics1994; 56; 377-399.

\section{Data Appendix}

The data used in the paper come from a variety of sources. They cover the 14 major states of India and span the financial years 1974-75 to 1996-97.

\subsection{Center-State Transfer Variables}

Transfers from the center to the states (various categories) are measured per capita in constant prices (1980-81 rupees). Three categories of central transfers are considered: the allocation of the proceeds of the central taxes as determined by the Finance Commission, grants on account of central plan schemes, and grants on account of centrally sponsored schemes. The nominal transfer data from the center to the states (various categories) are from the Reserve Bank of India Bulletin, an annual publication of the Reserve Bank of India. The nominal transfer data are deflated using the implicit state domestic product deflator (base year 1980-81), obtained from the National Accounts Statistics (Government of India, Ministry of Planning, Department of Statistics). The state population data, used to express magnitudes in per capita terms, are obtained from the National Accounts Statistics.

\subsection{Political Control Variables}

The center-state alignment dummy was coded from Butler et al (1996) and Grover and Arora (1998). The Vidhan Sabha swing dummy and the Lok Sabha swing dummy were coded, 
respectively, from Vidhan Sabha and Lok Sabha constituency-level electoral data, downloaded from the website of the Election Commission of India (http://eci.gov.in).

\subsection{Other Control Variables}

The 'other' control variables are: (i) annual rainfall, (ii) per capita state domestic product in constant prices (1980-81 rupees), (iii) the share of agriculture in state domestic product, (iv) state population, ( $\mathrm{v}$ ) the proportion of state population characterized as scheduled caste or scheduled tribe, and (vi) state's per capita allocation of the proceeds of central taxes, as determined by the Finance Commission, in constant prices (1980-81 rupees).

The annual rainfall data are from the Statistical Abstract of India (Government of India, Ministry of Planning, Department of Statistics). Data for variables (ii)-(iv) are from the National Accounts Statistics. The proportion of state population characterized as scheduled caste or scheduled tribe is estimated from the decennial Census of India (Government of India, Office of the Registrar General) for the years 1971, 1981, 1991 and 2001. Between any two successive censuses, total state population and scheduled caste/scheduled tribe population are

assumed to grow at a constant rate. For the variable (vi) data source, refer to "Center-State Transfer Variables." 
Table 1: Lok Sabha election outcomes 1962-1996

\begin{tabular}{|l|r|}
\hline Lok Sabha Election Year & Government Formation \\
\hline 1962 & Congress Party (Prime Minister: Jawaharlal Nehru) \\
\hline 1967 & Congress Party (Prime Minister: Indira Gandhi) \\
\hline 1971 & Congress Party (Prime Minister: Indira Gandhi) \\
\hline 1977 & Congress Party (Prime Minister: Indira Gandhi) \\
\hline 1980 & Congress Party (Prime Minister: Rajiv Gandhi) \\
\hline 1984 & National Front, a coalition of Janata Dal and regional parties (Prime Ministers: V.P. Singh and \\
Chandra Shekhar)
\end{tabular}


Table 2: Descriptive statistics 1974/75 - 1996/97

\begin{tabular}{|c|c|c|c|c|c|c|c|c|c|c|c|c|}
\hline \multirow[b]{2}{*}{ State } & \multicolumn{2}{|c|}{$\begin{array}{c}\text { Per Capita Grants: } \\
\text { Central Plan } \\
\text { Schemes }+ \\
\text { Centrally } \\
\text { Sponsored } \\
\text { Schemes } \\
\text { (in } 1980-81 \\
\text { rupees) } \\
{[1]}\end{array}$} & \multirow[t]{2}{*}{$\begin{array}{c}\text { Alignment } \\
\text { Variable } \\
\text { (March 31) } \\
\\
\\
{[2]} \\
\text { Mean }\end{array}$} & \multicolumn{2}{|c|}{$\begin{array}{c}\text { Annual } \\
\text { Rainfall } \\
\text { (in meters) }\end{array}$} & \multirow[t]{2}{*}{$\begin{array}{c}\text { State } \\
\text { Population } \\
\text { (in millions) } \\
\\
\\
{[4]} \\
\text { Mean }\end{array}$} & \multirow[t]{2}{*}{$\begin{array}{c}\text { Share of State } \\
\text { Population } \\
\text { characterized as } \\
\text { Scheduled Caste } \\
\text { or Scheduled } \\
\text { Tribe } \\
\\
{[5]} \\
\text { Mean }\end{array}$} & \multicolumn{2}{|c|}{$\begin{array}{c}\text { Per Capita } \\
\text { State Domestic } \\
\text { Product (in } \\
\text { 1980-81 rupees) }\end{array}$} & \multirow[t]{2}{*}{$\begin{array}{c}\text { Share of } \\
\text { Agriculture in } \\
\text { State Domestic } \\
\text { Product } \\
\text { (in percentage) } \\
\\
{[7]} \\
\text { Mean }\end{array}$} & \multicolumn{2}{|c|}{$\begin{array}{c}\text { Per Capita } \\
\text { Allocation of Central } \\
\text { Tax Proceeds, } \\
\text { determined by the } \\
\text { Finance Commission } \\
\text { (in 1980-81 rupees) } \\
{[8]}\end{array}$} \\
\hline & Mean & SD & & Mean & SD & & & Mean & SD & & Mean & SD \\
\hline Andhra Pradesh & 86.60 & 33.48 & 0.39 & 0.95 & 0.12 & 59.5 & 0.21 & 1355.22 & 139.25 & 39.3 & 293 & 79 \\
\hline Bihar & 60.35 & 33.92 & 0.70 & 1.28 & 0.13 & 77.8 & 0.23 & 607.36 & 60.93 & 43.8 & 321 & 111 \\
\hline Gujarat & 72.52 & 30.93 & 0.70 & 0.69 & 0.19 & 37.5 & 0.22 & 2949.73 & 412.46 & 30.2 & 227 & 65 \\
\hline Haryana & 88.58 & 32.10 & 0.87 & 0.70 & 0.17 & 14.6 & 0.19 & 8597.66 & 618.28 & 47.9 & 201 & 39 \\
\hline Karnataka & 81.92 & 32.03 & 0.39 & 1.85 & 0.40 & 40.8 & 0.19 & 2069.53 & 187.56 & 38.3 & 261 & 59 \\
\hline Kerala & 57.19 & 24.66 & 0.52 & 2.68 & 0.35 & 27.1 & 0.11 & 2523.62 & 283.35 & 34.9 & 242 & 56 \\
\hline Madhya Pradesh & 65.90 & 28.14 & 0.74 & 1.12 & 0.13 & 58.8 & 0.37 & 945.65 & 66.55 & 42.6 & 232 & 49 \\
\hline Maharashtra & 66.06 & 28.34 & 0.70 & 0.88 & 0.14 & 70.4 & 0.18 & 1669.00 & 183.36 & 23.1 & 218 & 30 \\
\hline Orissa & 86.15 & 32.01 & 0.78 & 1.44 & 0.20 & 28.8 & 0.38 & 1781.90 & 152.76 & 45.3 & 273 & 84 \\
\hline Punjab & 74.01 & 37.72 & 0.56 & 0.73 & 0.15 & 18.4 & 0.27 & 8892.37 & 586.59 & 46.4 & 241 & 48 \\
\hline Rajasthan & 115.61 & 57.27 & 0.65 & 0.54 & 0.12 & 38.9 & 0.29 & 1763.52 & 182.38 & 47.6 & 257 & 77 \\
\hline Tamil Nadu & 59.43 & 27.38 & 0.35 & 0.99 & 0.13 & 52.0 & 0.20 & 1455.10 & 229.48 & 23.7 & 260 & 54 \\
\hline Uttar Pradesh & 63.24 & 37.36 & 0.70 & 1.15 & 0.16 & 124.0 & 0.21 & 467.38 & 20.17 & 44.7 & 267 & 77 \\
\hline West Bengal & 38.69 & 18.02 & 0.13 & 2.05 & 0.33 & 60.8 & 0.28 & 1485.46 & 79.46 & 32.4 & 282 & 75 \\
\hline Average & 72.59 & 37.34 & 0.58 & 1.22 & 0.62 & 50.6 & 0.24 & 2611.68 & 2604.93 & 38.6 & 255 & 73 \\
\hline
\end{tabular}


Table 3 - Descriptive statistics of "Swing" measures

\begin{tabular}{|c|c|c|c|c|c|c|c|c|}
\hline & \multicolumn{4}{|c|}{ Proportion of constituencies with winning margin } & \multicolumn{4}{|c|}{ Proportion of times the state was a swing state } \\
\hline & \multicolumn{8}{|c|}{ State Elections - Vidhan Sabha } \\
\hline State & $\leq 1 \%$ & $\leq 2 \%$ & $\leq \mathbf{5 \%}$ & $\leq \mathbf{1 0 \%}$ & $\leq \mathbf{1 \%}$ & $\leq \mathbf{2 \%}$ & $\leq \mathbf{5 \%}$ & $\leq \mathbf{1 0 \%}$ \\
\hline Andhra Pradesh & 0.046 & 0.084 & 0.217 & 0.415 & 0.435 & 0.435 & 0.435 & 0.435 \\
\hline Bihar & 0.052 & 0.097 & 0.235 & 0.422 & 0.739 & 0.783 & 0.783 & 0.783 \\
\hline Gujarat & 0.029 & 0.068 & 0.155 & 0.301 & 0 & 0.087 & 0 & 0 \\
\hline Haryana & 0.061 & 0.105 & 0.233 & 0.422 & 0.609 & 0.609 & 0.609 & 0.609 \\
\hline Karnataka & 0.042 & 0.081 & 0.205 & 0.397 & 0.435 & 0.522 & 0.522 & 0.435 \\
\hline Kerala & 0.073 & 0.144 & 0.383 & 0.671 & 0.826 & 1 & 1 & 1 \\
\hline Madhya Pradesh & 0.037 & 0.083 & 0.203 & 0.384 & 0.304 & 0.348 & 0.348 & 0.304 \\
\hline Maharashtra & 0.038 & 0.069 & 0.190 & 0.372 & 0.217 & 0.130 & 0.304 & 0.348 \\
\hline Orissa & 0.034 & 0.067 & 0.169 & 0.330 & 0.522 & 0.478 & 0.261 & 0.261 \\
\hline Punjab & 0.046 & 0.088 & 0.245 & 0.452 & 0.391 & 0.435 & 0.783 & 0.783 \\
\hline Rajasthan & 0.051 & 0.094 & 0.218 & 0.397 & 0.565 & 0.565 & 0.696 & 0.609 \\
\hline Tamil Nadu & 0.040 & 0.085 & 0.199 & 0.360 & 0.435 & 0.435 & 0.435 & 0.435 \\
\hline Uttar Pradesh & 0.060 & 0.113 & 0.271 & 0.505 & 0.957 & 1 & 0.826 & 1 \\
\hline West Bengal & 0.029 & 0.067 & 0.160 & 0.328 & 0.174 & 0.174 & 0 & 0 \\
\hline \multirow[t]{2}{*}{ Average } & 0.046 & 0.089 & 0.220 & 0.411 & 0.472 & 0.5 & 0.5 & 0.5 \\
\hline & \multicolumn{8}{|c|}{ National Elections - Lok Sabha } \\
\hline Andhra Pradesh & 0.035 & 0.086 & 0.174 & 0.401 & 0.435 & 0.435 & 0.522 & 0.652 \\
\hline Bihar & 0.032 & 0.053 & 0.140 & 0.277 & 0.348 & 0.435 & 0.348 & 0.435 \\
\hline Gujarat & 0.031 & 0.076 & 0.161 & 0.384 & 0.130 & 0.348 & 0.478 & 0.478 \\
\hline Haryana & 0.088 & 0.112 & 0.164 & 0.413 & 0.652 & 0.435 & 0.435 & 0.522 \\
\hline Karnataka & 0.043 & 0.068 & 0.154 & 0.278 & 0.565 & 0.348 & 0.522 & 0.565 \\
\hline Kerala & 0.057 & 0.189 & 0.376 & 0.672 & 0.435 & 0.870 & 0.870 & 1 \\
\hline Madhya Pradesh & 0.020 & 0.049 & 0.133 & 0.259 & 0 & 0.217 & 0.217 & 0.217 \\
\hline Maharashtra & 0.016 & 0.031 & 0.120 & 0.260 & 0.087 & 0.087 & 0.217 & 0.435 \\
\hline Orissa & 0.021 & 0.081 & 0.173 & 0.325 & 0 & 0.348 & 0.478 & 0.478 \\
\hline Punjab & 0.043 & 0.094 & 0.167 & 0.314 & 0.565 & 0.435 & 0.565 & 0.435 \\
\hline Rajasthan & 0.024 & 0.064 & 0.160 & 0.304 & 0.130 & 0.348 & 0.435 & 0.565 \\
\hline Tamil Nadu & 0.012 & 0.023 & 0.080 & 0.140 & 0 & 0 & 0.217 & 0 \\
\hline Uttar Pradesh & 0.040 & 0.078 & 0.190 & 0.332 & 0.304 & 0.522 & 0.522 & 0.522 \\
\hline West Bengal & 0.082 & 0.106 & 0.246 & 0.469 & 0.565 & 0.348 & 0.435 & 0.435 \\
\hline Average & 0.039 & 0.079 & 0.174 & 0.345 & 0.301 & 0.37 & 0.447 & 0.481 \\
\hline
\end{tabular}


(i) The top half of Panel [1] refers to Vidhan Sabha elections. Column $[1](\leq 1 \%)$, Column $[2](\leq 2 \%)$, Column $[3](\leq 5 \%)$ and Column $[4](\leq 10 \%)$ show, respectively, the state-specific means of vswing01, vswing02, vswing05 and vswing10. See text for details.

(ii) The bottom half of Panel [1] refers to Lok Sabha elections. Column $[1](\leq 1 \%)$, Column $[2](\leq 2 \%)$, Column $[3](\leq 5 \%)$ and Column $[4](\leq 10 \%)$ show, respectively, the state-specific means of lswing01, lswing02, lswing05 and lswing10. See text for details.

(iii) The top half of Panel [2] refers to Vidhan Sabha elections. Fix a state-financial year. The state-financial year is coded as 'swing' if the proportion of Vidhan Sabha constituencies in the state that are 'swing' is greater than the median value for the proportion taken over all states in the given financial year. In Column [1] $(\leq 1 \%)$, Column [2] $(\leq 2 \%)$, Column [3] $(\leq 5 \%)$ and Column [4] $(\leq 10 \%)$, a Vidhan Sabha constituency is defined as 'swing' if the winning margin is weakly less than, respectively, 1 percent, 2 percent, 5 percent and 10 percent. Thus, Column [1], [2], [3] and [4] show, respectively, the state-specific means of vswingdum01, vswingdum02, vswingdum05 and vswingdum10. See text for details.

(iv) The bottom half of Panel [2] refers to Lok Sabha elections. Fix a state-financial year. The state-financial year is coded as 'swing' if the proportion of Lok Sabha constituencies in the state that are 'swing' is greater than the median value for the proportion taken over all states in the given financial year. In Column [1] $(\leq 1 \%)$, Column [2] $(\leq 2 \%)$, Column [3] $(\leq 5 \%)$ and Column [4] $(\leq 10 \%)$, a Lok Sabha constituency is defined as 'swing' if the winning margin is weakly less than, respectively, 1 percent, 2 percent, 5 percent and 10 percent. Thus, Column [1], [2], [3] and [4] show, respectively, the statespecific means of lswingdum01, lswingdum02, Iswingdum05 and lswingdum10. See text for details. 
Table 4: Least squares (within-group estimation) results for per capita grants

\begin{tabular}{|c|c|c|c|c|c|c|}
\hline & $\begin{array}{c}\text { Basic Model } \\
\text { Without 'Other } \\
\text { Controls' } \\
{[1]}\end{array}$ & Basic Model & $\begin{array}{c}\text { Variant } 1 \\
{[3]} \\
\end{array}$ & Variant 2 & $\begin{array}{c}\text { Variant } 3 \\
{[5]}\end{array}$ & $\begin{array}{c}\text { Variant } 4 \\
{[6]}\end{array}$ \\
\hline$A L^{*} V S W^{*} L S W$ & $0.135(1.87)$ & $0.179(2.58)$ & $0.188(2.80)$ & $0.177(2.52)$ & $0.222(2.76)$ & \\
\hline$A L^{*} V S W^{*}(1-L S W)$ & $0.087(1.30)$ & $0.130(2.09)$ & $0.140(2.23)$ & $0.118(1.84)$ & $0.190(2.75)$ & \\
\hline$A L^{*}(1-V S W) * L S W$ & $-0.057(0.75)$ & $-0.026(0.37)$ & $-0.002(0.02)$ & $-0.040(0.55)$ & $0.051(0.65)$ & \\
\hline$A L^{*}(1-V S W)^{*}(1-L S W)$ & $-0.041(0.06)$ & $-0.005(0.10)$ & $0.001(0.16)$ & $-0.033(0.54)$ & $0.096(1.60)$ & \\
\hline$(1-A L) * V S W^{*} L S W$ & $0.005(0.08)$ & $0.011(0.15)$ & $0.019(0.25)$ & $0.019(0.27)$ & $0.040(0.49)$ & \\
\hline$(1-A L)^{*} V S W^{*}(1-L S W)$ & $0.039(0.69)$ & $0.035(0.60)$ & $0.023(0.38)$ & $0.038(0.65)$ & $0.093(1.31)$ & \\
\hline$(1-A L) *(1-V S W) * L S W$ & $0.004(0.05)$ & $-0.012(0.17)$ & $-0.019(0.24)$ & $-0.008(0.11)$ & $0.023(0.30)$ & \\
\hline Alignment Dummy & & & & & & $0.055(1.38)$ \\
\hline $\begin{array}{l}\text { Proportion of constituencies in } \\
\text { the state that are swing in } \\
\text { the last state election }\end{array}$ & & & & & & $1.470(2.38)$ \\
\hline $\begin{array}{l}\text { Proportion of constituencies in } \\
\text { the state that are swing in } \\
\text { the last national election }\end{array}$ & & & & & & $0.190(0.59)$ \\
\hline $\mathrm{R}^{2}$ (within group) & 0.850 & 0.860 & 0.861 & 0.853 & 0.861 & 0.856 \\
\hline Alignment Date & March 31 & March 31 & March 1 & March 31 & March 31 & March 31 \\
\hline Finance Commission grant & Excluded & Included & Included & Excluded & Included & Included \\
\hline $\begin{array}{l}\text { President's Rule included in } \\
\text { the definition of Alignment }\end{array}$ & No & No & No & No & Yes & No \\
\hline
\end{tabular}


The dependent variable is the natural log of per capita grants in 1980-81 rupees, where grants is defined as the sum of central plan scheme grants and centrally sponsored scheme grants. There are 14 states observed over 23 years in the sample. Specification [1] only includes state and time dummies. All the other regressions also include the following variables: $\ln$ (annual rainfall), $\ln$ (state population), proportion of state population characterized as scheduled caste or scheduled tribe, $\ln$ (per capita state domestic product (in constant 1980-81 rupees)), the share of agriculture in state domestic product, and, in some specifications, the $\ln$ (per capita allocation of central tax proceeds, as determined by the Finance Commission (in constant 1980-81 rupees)).

(ii) Fix a state-financial year. VSW takes the value of 1 if the proportion of Vidhan Sabha constituencies in the state that are 'swing' is greater than the median value for the proportion taken over all states in the given financial year. A constituency is defined as 'swing' if the winning margin is less than or equal to 1 percent.

(iii) Fix a state-financial year. $L S W$ takes the value of 1 if the proportion of Lok Sabha constituencies in the state that are 'swing' is greater than the median value for the proportion taken over all states in the given financial year. A constituency is defined as 'swing' if the winning margin is less than or equal to 1 percent.

(iv) Fix a state-financial year. AL takes the value of 1 if the central and state governments on a specified date (March 1 of the previous financial year in Column [3] and March 31 of the previous financial year in Columns [1], [2], [4], [5] and [6]) share at least one political party in common; the treatment of President's Rule in the construction of AL is given in the final row of Table 4.

(v) The absolute t-ratios given in parentheses are based on robust standard errors that correct for clustering at the state level. 
Table 5: Least squares (within-group estimation) results for per capita grants - Sensitivity to changes in cutoff margins

\begin{tabular}{|l|c|c|c|c|}
\hline & Definition of Vidhan Sabha swing dummy, VSW, based on winning margin being less than: \\
\hline & $1 \%[1]$ & $2 \%[2]$ & $5 \%[3]$ & $10 \%[4]$ \\
\hline$A L^{*} V S W$ & $0.148(2.63)$ & $0.050(0.81)$ & $0.040(0.69)$ & $0.083(1.44)$ \\
\hline$A L^{*}(1-V S W)$ & $-0.007(0.14)$ & $-0.004(0.07)$ & $0.009(0.17)$ & $-0.002(0.04)$ \\
\hline$(1-A L) * V S W$ & $0.031(0.67)$ & $-0.063(1.13)$ & $-0.057(1.02)$ & $-0.031(0.57)$ \\
\hline \hline $\mathrm{R}^{2}($ Within group) & 0.860 & 0.855 & 0.854 & 0.856 \\
\hline \hline
\end{tabular}

Notes:

(i) The model in [1] is the same as [2] in Table 4 excluding the Lok Sabha swing dummy.

(ii) Fix a state-financial year. $A L$ takes the value of 1 if the central and state governments on March 31 of the previous financial year share at least one political party in common and there is no President's Rule in the state on that date.

(iii) Fix a state-financial year. VSW takes the value of 1 if the proportion of Vidhan Sabha constituencies in the state that are 'swing' is greater than the median value for the proportion taken over all states in the given financial year. In Column [1], [2], [3] and [4] a constituency is defined as 'swing' if the winning margin is weakly less than, respectively, 1 percent, 2 percent, 5 percent and 10 percent.

(iv) Also see notes to Table 4. 
Appendix Table 1: Alignment and Swing dummies using one percent cutoff used in the basic regression

\begin{tabular}{|c|c|c|c|c|c|c|c|c|c|c|c|c|c|c|c|c|c|c|c|c|c|c|c|c|}
\hline State & & 1974 & 1975 & 1976 & 1977 & 1978 & 1979 & 1980 & 1981 & 1982 & 1983 & 1984 & 1985 & 1986 & 1987 & 1988 & 1989 & 1990 & 1991 & 1992 & 1993 & 1994 & 1995 & 1996 \\
\hline \multirow[t]{3}{*}{ Andhra } & $\overline{\mathrm{AL}}$ & 1 & 1 & 1 & 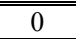 & 0 & 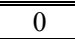 & 1 & 11 & 11 & 0 & 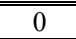 & 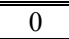 & 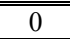 & 0 & 0 & 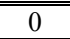 & 0 & 0 & 11 & 11 & 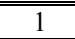 & 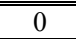 & 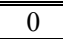 \\
\hline & VS & 0 & 0 & 0 & 0 & 1 & 1 & 1 & 1 & 1 & 0 & 0 & 0 & 0 & 0 & 0 & 0 & 1 & 1 & 1 & 1 & 1 & 0 & 0 \\
\hline & LS & 0 & 0 & 0 & 0 & 0 & 0 & 0 & 0 & 0 & 0 & 0 & 1 & 1 & 1 & 1 & 1 & 0 & 0 & 1 & 1 & 1 & 1 & 1 \\
\hline \multirow[t]{3}{*}{ Bihar } & $\overline{\mathrm{AL}}$ & 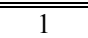 & 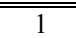 & 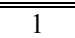 & 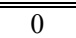 & 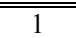 & $\bar{~} \overline{11}$ & 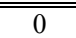 & 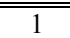 & 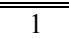 & 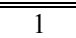 & 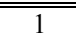 & 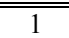 & $\bar{~}$ & $\bar{~}$ & 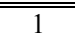 & $\bar{~}$ & 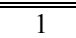 & 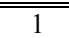 & 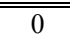 & 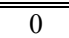 & 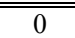 & 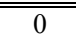 & 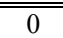 \\
\hline & VS & 0 & 0 & 0 & 0 & 1 & 1 & 1 & 1 & 1 & 1 & 1 & 1 & 1 & 1 & 1 & 1 & 1 & 1 & 1 & 1 & 1 & 0 & 0 \\
\hline & LS & 1 & 1 & 1 & 0 & 0 & 0 & 1 & 1 & 1 & 1 & 1 & 0 & 0 & 0 & 0 & 0 & 0 & 0 & 0 & 0 & 0 & 0 & 0 \\
\hline \multirow[t]{3}{*}{ Gujarat } & $\overline{\mathrm{AL}}$ & 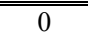 & $\bar{~} 0$ & 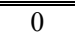 & 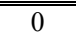 & 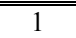 & 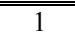 & 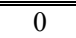 & 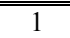 & 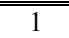 & 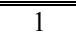 & 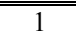 & 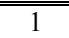 & 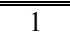 & 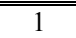 & 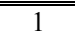 & 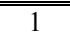 & 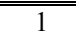 & 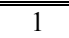 & 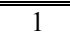 & 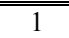 & 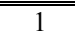 & 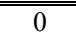 & 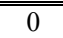 \\
\hline & VS & 0 & 0 & 0 & 0 & 0 & 0 & 0 & 0 & 0 & 0 & 0 & 0 & 0 & 0 & 0 & 0 & 0 & 0 & 0 & 0 & 0 & 0 & 0 \\
\hline & LS & 0 & 0 & 0 & 1 & 1 & 1 & 0 & 0 & 0 & 0 & 0 & 0 & 0 & 0 & 0 & 0 & 0 & 0 & 0 & 0 & 0 & 0 & 0 \\
\hline \multirow[t]{3}{*}{ Haryana } & $\overline{\mathrm{AL}}$ & $\bar{~} \overline{1}$ & $\bar{~} \overline{1}$ & 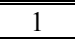 & 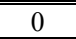 & $\bar{~} \overline{1}$ & 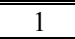 & 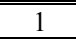 & 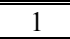 & 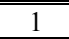 & $\overline{\overline{11}}$ & 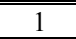 & 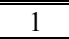 & $\bar{~} \overline{1}$ & 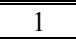 & 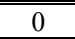 & 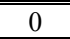 & 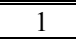 & 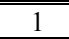 & 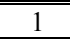 & 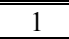 & 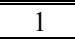 & 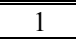 & 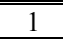 \\
\hline & VS & 1 & 1 & 1 & 1 & 0 & 0 & 0 & 0 & 0 & 1 & 1 & 1 & 1 & 1 & 0 & 0 & 0 & 0 & 1 & 1 & 1 & 1 & 1 \\
\hline & LS & 1 & 1 & 1 & 0 & 0 & 0 & 1 & 1 & 1 & 1 & 1 & 1 & 1 & 1 & 1 & 1 & 1 & 1 & 0 & 0 & 0 & 0 & 0 \\
\hline \multirow[t]{3}{*}{ Karnataka } & $\overline{\mathrm{AL}}$ & $\overline{11}$ & 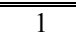 & 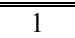 & 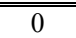 & 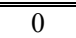 & 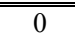 & $\bar{~} 1$ & $\bar{~} 1$ & 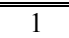 & 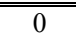 & 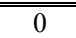 & 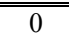 & 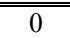 & 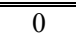 & 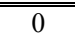 & 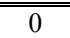 & 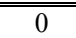 & 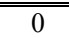 & $\bar{~} 1$ & $\bar{~} \overline{1}$ & $\bar{~} 1$ & 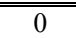 & 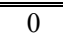 \\
\hline & VS & 0 & 0 & 0 & 0 & 1 & 1 & 1 & 0 & 0 & 0 & 0 & 1 & 1 & 1 & 1 & 1 & 0 & 0 & 0 & 0 & 0 & 1 & 1 \\
\hline & LS & 0 & 0 & 0 & 1 & 1 & 1 & 0 & 0 & 0 & 0 & 0 & 1 & 1 & 1 & 1 & 1 & 0 & 0 & 1 & 1 & 1 & 1 & 1 \\
\hline \multirow[t]{3}{*}{ Kerala } & 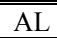 & 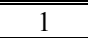 & 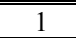 & 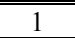 & 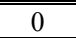 & 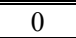 & 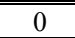 & 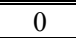 & 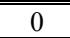 & 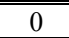 & 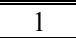 & 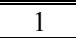 & 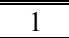 & 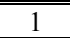 & 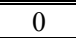 & $\overline{00}$ & $\overline{00}$ & $\overline{00}$ & 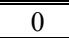 & 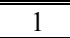 & 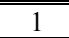 & 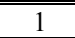 & 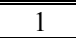 & 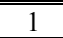 \\
\hline & VS & 1 & 1 & 1 & 1 & 0 & 0 & 1 & 1 & 1 & 1 & 1 & 1 & 1 & 1 & 1 & 1 & 0 & 0 & 1 & 1 & 1 & 1 & 1 \\
\hline & LS & 0 & 0 & 0 & 1 & 1 & 1 & 1 & 1 & 1 & 1 & 1 & 0 & 0 & 0 & 0 & 0 & 1 & 1 & 0 & 0 & 0 & 0 & 0 \\
\hline \multirow[t]{3}{*}{ MP } & $\overline{\mathrm{AL}}$ & 1 & 1 & 1 & 0 & 1 & 1 & 0 & 1 & 1 & 1 & 1 & 1 & 1 & 1 & 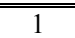 & 1 & 0 & 0 & 0 & 0 & 1 & $\bar{~} 1$ & 1 \\
\hline & VS & 1 & 1 & 1 & 1 & 0 & 0 & 0 & 0 & 0 & 0 & 0 & 0 & 0 & 0 & 0 & 0 & 0 & 0 & 0 & 0 & 1 & 1 & 1 \\
\hline & LS & 0 & 0 & 0 & 0 & 0 & 0 & 0 & 0 & 0 & 0 & 0 & 0 & 0 & 0 & 0 & 0 & 0 & 0 & 0 & 0 & 0 & 0 & 0 \\
\hline \multirow[t]{3}{*}{ Maharashtra } & $\overline{\mathrm{AL}}$ & $\bar{~} 1$ & $\bar{~} 1$ & 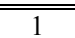 & 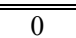 & 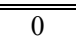 & 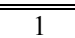 & 0 & $\overline{11}$ & 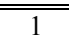 & 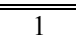 & 11 & 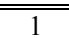 & $\bar{~} 1$ & $\overline{11}$ & 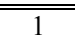 & $\bar{~} 1$ & 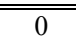 & 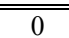 & $\overline{11}$ & $\overline{11}$ & 11 & 0 & 0 \\
\hline & VS & 0 & 0 & 0 & 0 & 1 & 1 & 1 & 0 & 0 & 0 & 0 & 0 & 0 & 0 & 0 & 0 & 1 & 1 & 0 & 0 & 0 & 0 & 0 \\
\hline & LS & 0 & 0 & 0 & 0 & 0 & 0 & 0 & 0 & 0 & 0 & 0 & 0 & 0 & 0 & 0 & 0 & 1 & 1 & 0 & 0 & 0 & 0 & 0 \\
\hline \multirow[t]{3}{*}{ Orissa } & $\overline{\mathrm{AL}}$ & 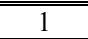 & $\bar{~} \overline{1}$ & $\bar{~} \overline{11}$ & $\overline{00}$ & $\bar{~} \overline{1}$ & $\bar{~} \overline{1}$ & $\overline{00}$ & 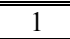 & $\bar{~} \overline{1}$ & $\bar{~} 1$ & $\bar{~} \overline{1}$ & $\overline{11}$ & $\bar{~} \overline{1}$ & 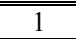 & $\bar{~} \overline{1}$ & $\bar{~} \overline{1}$ & $\bar{~} \overline{1}$ & $\bar{~} \overline{1}$ & $\overline{00}$ & $\overline{00}$ & $\overline{00}$ & 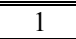 & $\bar{~} \overline{11}$ \\
\hline & VS & 1 & 1 & 1 & 1 & 1 & 1 & 1 & 0 & 0 & 0 & 0 & 0 & 1 & 1 & 1 & 0 & 0 & 0 & 0 & 0 & 0 & 1 & 1 \\
\hline & LS & 0 & 0 & 0 & 0 & 0 & 0 & 0 & 0 & 0 & 0 & 0 & 0 & 0 & 0 & 0 & 0 & 0 & 0 & 0 & 0 & 0 & 0 & 0 \\
\hline \multirow[t]{3}{*}{ Punjab } & $\overline{\mathrm{AL}}$ & $\bar{~} \overline{11}$ & $\bar{~} \overline{11}$ & 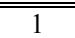 & 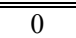 & 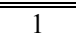 & 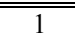 & 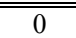 & 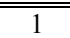 & 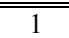 & 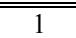 & 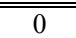 & 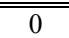 & 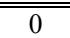 & 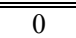 & 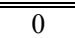 & 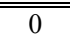 & 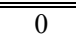 & 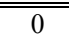 & 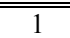 & 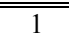 & 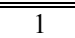 & 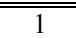 & 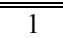 \\
\hline & VS & 1 & 1 & 1 & 1 & 0 & 0 & 0 & 1 & 1 & 1 & 1 & 1 & 0 & 0 & 0 & 0 & 0 & 0 & 0 & 0 & 0 & 0 & 0 \\
\hline & LS & 1 & 1 & 1 & 0 & 0 & 0 & 0 & 0 & 0 & 0 & 0 & 1 & 1 & 1 & 1 & 1 & 0 & 0 & 1 & 1 & 1 & 1 & 1 \\
\hline \multirow[t]{3}{*}{ Rajasthan } & $\overline{\mathrm{AL}}$ & 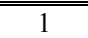 & 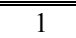 & 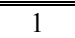 & 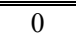 & 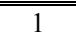 & 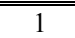 & 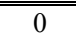 & $\bar{~} 1$ & 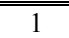 & 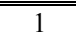 & 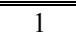 & 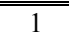 & 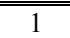 & $\bar{~} 1$ & 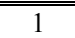 & 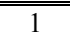 & 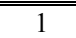 & 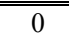 & 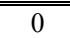 & 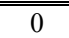 & 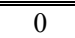 & 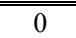 & $\bar{~} 0$ \\
\hline & VS & 0 & 0 & 0 & 0 & 0 & 0 & 0 & 1 & 1 & 1 & 1 & 1 & 1 & 1 & 1 & 1 & 1 & 1 & 1 & 1 & 0 & 0 & 0 \\
\hline & LS & 1 & 1 & 1 & 0 & 0 & 0 & 0 & 0 & 0 & 0 & 0 & 0 & 0 & 0 & 0 & 0 & 0 & 0 & 0 & 0 & 0 & 0 & 0 \\
\hline \multirow[t]{3}{*}{ Tamil Nadu } & $\overline{\mathrm{AL}}$ & $\overline{00}$ & $\overline{00}$ & $\overline{00}$ & $\overline{00}$ & $\overline{00}$ & 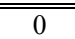 & 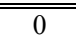 & $\overline{00}$ & 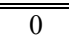 & 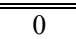 & 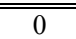 & 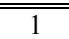 & $\bar{~} 1$ & 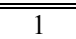 & 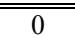 & $\overline{00}$ & 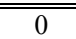 & 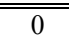 & $\bar{~} 1$ & $\bar{~} 1$ & $\bar{~} 1$ & $\bar{~} 1$ & $\bar{~} 1$ \\
\hline & VS & 0 & 0 & 0 & 0 & 1 & 1 & 1 & 1 & 1 & 1 & 1 & 0 & 0 & 0 & 0 & 1 & 1 & 1 & 0 & 0 & 0 & 0 & 0 \\
\hline & LS & 0 & 0 & 0 & 0 & 0 & 0 & 0 & 0 & 0 & 0 & 0 & 0 & 0 & 0 & 0 & 0 & 0 & 0 & 0 & 0 & 0 & 0 & 0 \\
\hline \multirow[t]{3}{*}{ UP } & $\overline{\mathrm{AL}}$ & 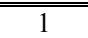 & 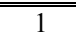 & 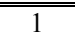 & 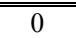 & $\bar{~} 1$ & 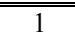 & 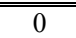 & $\bar{~} 1$ & 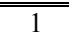 & 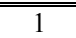 & 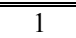 & 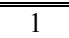 & 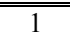 & 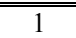 & $\bar{~} 1$ & 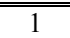 & 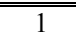 & 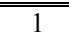 & 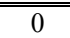 & $\overline{00}$ & 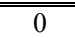 & 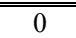 & 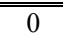 \\
\hline & VS & 1 & 1 & 1 & 1 & 1 & 1 & 0 & 1 & 1 & 1 & 1 & 1 & 1 & 1 & 1 & 1 & 1 & 1 & 1 & 1 & 1 & 1 & 1 \\
\hline & LS & 0 & 0 & 0 & 0 & 0 & 0 & 0 & 0 & 0 & 0 & 0 & 0 & 0 & 0 & 0 & 0 & 1 & 1 & 1 & 1 & 1 & 1 & 1 \\
\hline \multirow[t]{3}{*}{ "West Bengal } & $\overline{\mathrm{AL}}$ & $\overline{11}$ & $\overline{11}$ & $\overline{11}$ & 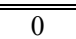 & 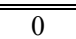 & 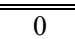 & 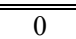 & 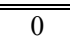 & $\overline{00}$ & 0 & 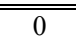 & 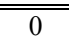 & 0 & 0 & 0 & 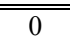 & 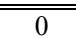 & 0 & 0 & 0 & 0 & 0 & 0 \\
\hline & VS & 1 & 1 & 1 & 1 & 0 & 0 & 0 & 0 & 0 & 0 & 0 & 0 & 0 & 0 & 0 & 0 & 0 & 0 & 0 & 0 & 0 & 0 & 0 \\
\hline & LS & 1 & 1 & 1 & 0 & 0 & 0 & 0 & 0 & 0 & 0 & 0 & 1 & 1 & 1 & 1 & 1 & 0 & 0 & 1 & 1 & 1 & 1 & 1 \\
\hline
\end{tabular}


(i) The decision date used is March 31.

(ii) Fix a state-financial year. $A L$ takes the value of 1 if the central and state governments on March 31 of the previous financial year share at least one political party in common and there is no President's Rule in the state on that date.

(iii) Fix a state-financial year. VS (LS) takes the value of 1 if Vidhan Sabha (Lok Sabha) election outcomes result in the state being classified as a swing state in the given financial year. A state is defined as a swing state if the proportion of constituencies in the state that are swing (winning margin less than or equal to one percent) is greater than the median value for the proportion taken over all states in the given financial year.

(iv) MP (see the column showing state names) refers to Madhya Pradesh; UP refers to Uttar Pradesh. 